Vol. 4, No. 1, 2018

Bohdan Diveyev

Department of Transport Technologies, Lviv Polytechnic National University, 12, Stepan Bandera Str., Lviv, Ukraine, E-mail: divboglviv@yahoo.com

\title{
SEMI-ACTIVE VIBRATION ABSORBERS FOR THE HIGH-RISE OBJECTS
}

Received: February 08, 2018 / Revised: May 11, 2018 / Accepted: June 26, 2018

(C) Diveyev B., 2018

\begin{abstract}
To determine the optimal parameters of the dynamic vibration absorber (DVA), a complete multi-parameter model of the dynamics of machines and structures is required. A model with two degrees of freedom is unacceptable for a sufficiently precise calculation with sufficient accuracy of the oscillations of the design, and thus for an adequate description of its dynamic characteristics. Therefore, in practice, it is necessary to investigate the design using a complex model. In particular, the methods for determining the concentration of mass and stiffness can be used on the basis of a refined theoretical calculation. A number of numerical schemes (NS) are known for complex vibro-loaded structures, in which developed methods of decomposition and synthesis of NS based on new methods of modal synthesis. Also developed is a complex NS of discrete-continuum type, which provides an opportunity in the adaptive mode to calculate stresses not only in the continuum elements, but also in the places of their greatest concentration - in the compounds.

In this paper, an efficient numerical approach based on the theoretical-experimental method is proposed to maximize the minimal damping of modes in a prescribed frequency range for general viscous tuned-mass systems. Methods of decomposition and numerical synthesis are considered on the basis of the adaptive schemes. The influence of dynamic vibration absorbers and basic design elastic and damping properties is under discussion. A technique is developed to give the optimal DVA's for the elimination of excessive vibration in sinusoidal and impact forced tall buildings system. One task of this work is to analyze parameters identification of the dynamic vibration absorber and the basic structure. The discrete-continue models of machines dynamics of some elongated element with multi mass DVA's are offered. A technique is developed to give the optimal DVA's for the elimination of excessive vibration in harmonic stochastic and impact loaded systems. The questions of robustness at optimization of DVA are considered. Different types of control management for semi-active DVA's are applied. Examples of DVA's practical implementation are presented.
\end{abstract}

Keywords: dynamic vibration absorber, semi-active absorber, high-rise object, adaptive scheme, optimization, robustness, design.

\section{Introduction}

Vibration in machines and structures plays a negative role, with the exception of the class of machines that use vibration to carry out technological processes (vibro-transporters, vibro-condensers, vibrating machines, etc.). About $70 \%$ of structures are destroyed due to the effects of vibration. Hazardous vibration for the human body causes a variety of diseases and greatly reduces efficiency and comfort, even with minor vibration loads. The following are the main ways of reducing vibration in buildings and machines: 1) reduction of vibration in the source of its occurrence; 2) absorption of vibration in the way of its propagation; 3) rational design of the design in order to avoid resonance phenomena; 4) vibration absorption with the help of special devices, for example, dynamic vibration absorbers (DVA's).

The first three methods require significant structural changes and costs. Vibration absorption is much more economical and efficient. In this paper, we consider the last way to increase the resource and efficiency of machines and structures. 
Damping the vibrations of buildings and structures, machines and appliances, their individual structures and elements is an important scientific and technical problem in many fields of technology industrial and civil engineering, shipbuilding, aircraft engineering, transport and power engineering. Reducing the amplitudes of oscillations can significantly increase fatigue strength, reliability and durability of structures, improve the technical conditions of their operation. In this regard, the development of effective tools and methods of vibration protection is one of the major problems in the dynamics of structures and machines.

Given the diversity of types of dynamic processes that cause increased vibrations and increased operational requirements, the development of methods and means of vibration protection, in particular passive ones or controlled remains relevant. Among them, a special place is occupied by DVA, which are joined to the design in order to reduce its vibration load. A special feature of DVA is that their use can be foreseen at the design and construction stage, and in case of elimination of unsatisfactory characteristics of the structure already in the process of its operation.

One of the main directions of the development of the theory of fading oscillations is to evaluate their efficiency and to select optimal parameters with different disturbing loads. To date, the theory of singlemass linear DVA with viscous and independent friction with harmonic oscillations with stable or fixed frequency (which varies in time) is most fully developed.

\section{Energy Scattering and Its Simulation}

In addition to DVA's, various devices for absorbing oscillation energy are widely used in machines designs. The book [1] presents various devices for scattering energy in buildings under seismic loading. This, all kinds of dampers: dampers with viscous, dry friction, liquid dampers. Different types and DVA's are also considered. Damping is considered both on the basis of a linearly viscous model and a hysteresis for nonlinear oscillations.

Damping is a difficult process. Some basics can be found in [2-5]. The type of energy into which the mechanical energy is transformed is dependent on the system and the physical mechanism that cause the dissipation. For most vibrating system, a significant part of the energy is converted into heat. The specific ways in which energy is dissipated in vibration are dependent upon the physical mechanisms active in the structure. These physical mechanisms are complicated physical process that is not totally understood. The types of damping that are present in the structure will depend on which mechanisms predominate in the given situation. Thus, any mathematical representation of the physical damping mechanisms in the equations of motion of a vibrating system will have to be a generalization and approximation of the true physical situation. The expression similar to this equation have been discussed in [6] in the context of viscoelastic systems. This equations shows a linear dependence of the loss factor on the driving frequency. This dependence has been discussed by [7] where it has been pointed out that the frequency dependence, observed in practice, is usually not of this form. In such cases one often resorts to an equivalent ideal dashpot. Theoretical objections to the approximately constant value of damping over a range of frequency, as observed in aero-elasticity problems, have been raised. This representation however has some serious physical limitations. [8-10] have pointed out that such a representation violates causality, a principle which asserts that the states of a system at a given point of time can be affected only by the events in the past and not by those of the future.

In this paper, the basic model of the linear viscoelastic body and the analogy of the viscoelastic system to elastic under constant oscillations are used. In systems with dry friction by the method of numerical experiment in real time are the frequency characteristics of DVA. Of course, the issue of energy scattering in solids or liquids is rather complicated and is not part of the scope of research data.

\section{Problem Statement. Design of DVA}

Consider first the general scheme of quenching oscillations. Fig. 1 shows the general scheme of quenching vibration. Here on some body A there is a certain system of forces. For vibration extinguishing, a system of DVA of two types is used: discrete DVA (dDVA), and continual DVA (cDVA). Small arrows show DVA with energy influence. It can be like all sorts of discrete DVA's controlled by magnetic fields, and continual, such as piezoelectric cells. Also, great arrows show the energy supply regardless of DVA. 
This is all sorts of active vibration controllers. Vibration sensitive elements (SE) are also shown here. In the numerical implementation of the optimization scheme, it is necessary to choose the geometry of the location and parameters of the DVA, and the parameters of the DVA can vary in time, as well as external influences and parameters of sensitive elements.

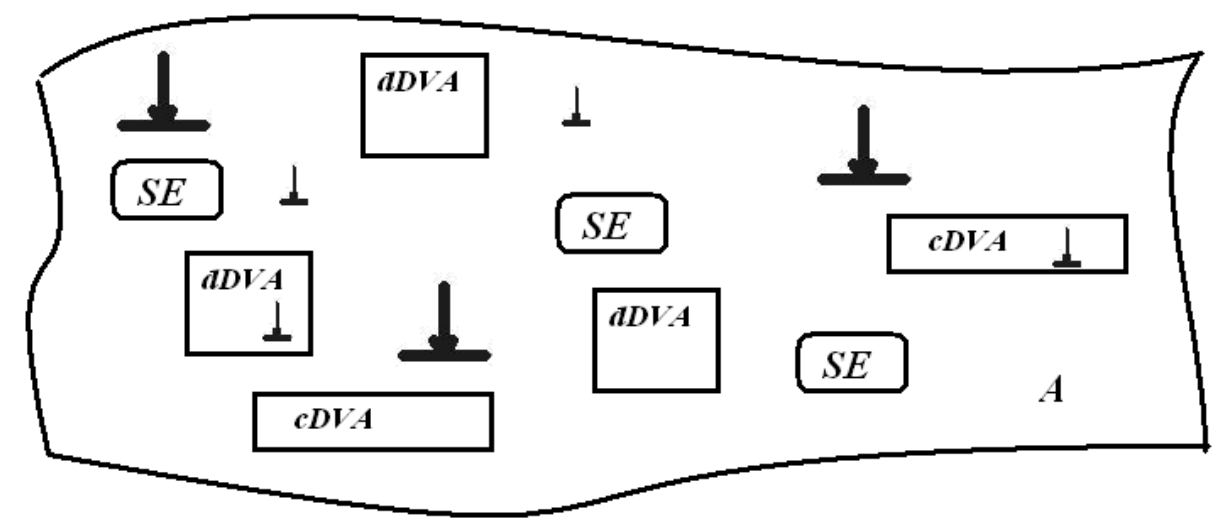

Fig. 1. General scheme of vibration extinguishing

Among the sensitive elements, a ranking has been introduced. Indicate the effectiveness of vibration protection for each of the SE through $E_{S E i}$. This may be the maximum stress, displacement, or some integral characteristic in this element. The total effectiveness of vibration protection is denoted by $E_{S E}$, and we define it as some sum of the individual $E_{S E i}$ with coefficients of importance $\lambda_{i}$.

$$
E_{S E}=\sum_{i} \lambda_{i} E_{S E i}
$$

Of course, the improvement of criterion (1) can be achieved at the stage of design without the use of DVA. However, this often requires high costs of materials and, in general, is often impossible.

Here all the parameters of DVA's are some time-controlled processes, correlated with external disturbances. An important role is played by the mathematical models of the quenching process. Preferably, we consider simple discrete models, but often we must take into account the distributed fields of displacement and stress. Numerical methods of these fields are also discretized, either on the basis of FEM, or by spectral methods [11-19].

Systems of equations of finite dimension are obtained in spatial coordinates. The axis of time is generally not discretized. Processes in time are considered as harmonic, impulsive, stochastic. As a result, a system of nonlinear equations is obtained

$$
\frac{d^{2} q_{S}}{d t^{2}}=F_{S}\left(q_{S}, . q_{D}, . q_{A}\right), \frac{d^{2} q_{D}}{d t^{2}}=F_{D}\left(q_{S}, . q_{D}, . q_{A}\right), \frac{d^{2} q_{A}}{d t^{2}}=F_{A}\left(q_{S}, . q_{D}, . q_{A}\right),
$$

where $q_{S}$ is the movement vector of the SE. According to our scheme, he has a look $q_{S}=\left(q_{S 1}, q_{S 2}, \ldots, q_{S N}\right)$. Similarly, you can write and - the vector of DVA's displacements $q_{D}, q_{D}=\left(q_{D 1}, q_{D 2}, \ldots, q_{D M}\right)$. Vector $q_{A}$ is a vector of system parameters that are not included in the first two sets. Now criterion (1) can be written as follows

$$
E_{S E}=\sum_{i} \lambda_{i} E_{S E i}\left(q_{S}, q_{D}, q_{A}\right) .
$$

Sometimes you can simplify (3). If the interaction of sensitive elements is small, then

$$
E_{S E}=\sum_{i} \lambda_{i} E_{S E i}\left(q_{S i}, q_{D}, q_{A}\right) \text {. }
$$

It should be noted that not only the parameters of the DVA, but also the geometry of their location, have a great influence. For example, for long-console constructions, as will be shown, it is possible for a much lighter DVA to get a good result. 
It is important to determine the parameters of the system (2). This, of course, is a classical identification scheme in mechanics. However, in this perspective (rice), this task, as will be shown, acquires specifics.

Design of DVA can be divided into the following stages (Fig. 2).

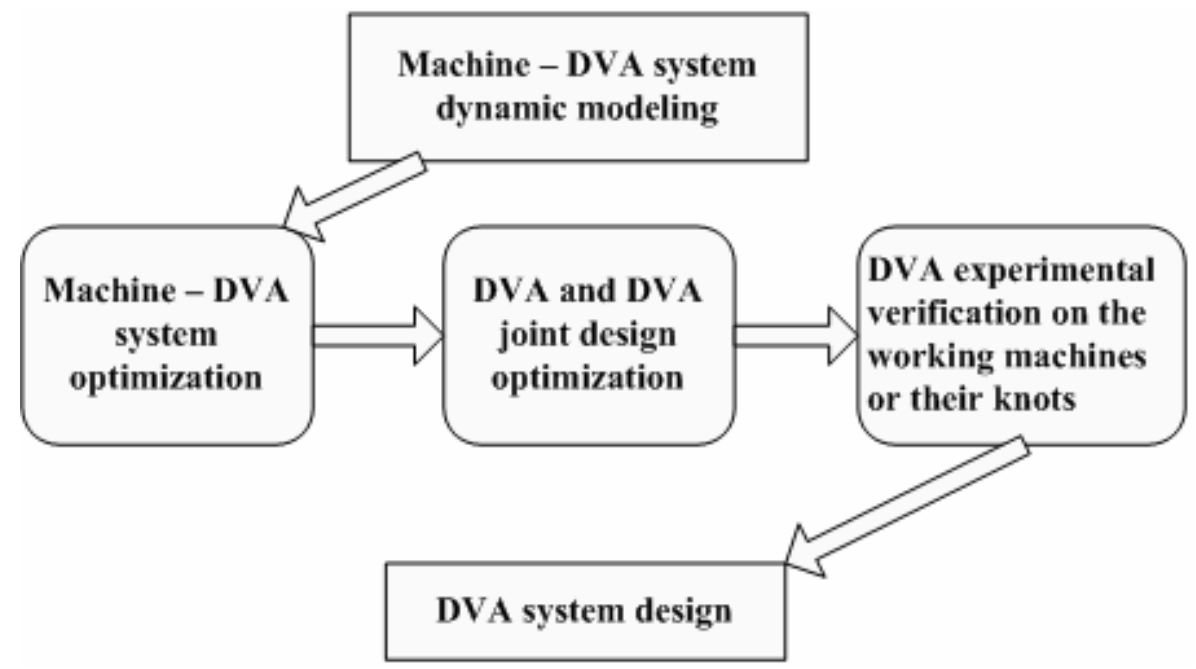

Fig. 2. Scheme of system design of the machine - DVA

Let's single out the main criteria of optimality of the DVA design (Fig. 3). This is far from a complete list of criteria for optimality. He, as in the case of any design, can be replenished with a number of others, for example, repair capacity, aesthetics of design, etc. In our opinion, not least the criterion as the simplicity of the design, which, in its turn, allows at the project stage to predict the value of the constructive parameters of the DVA.

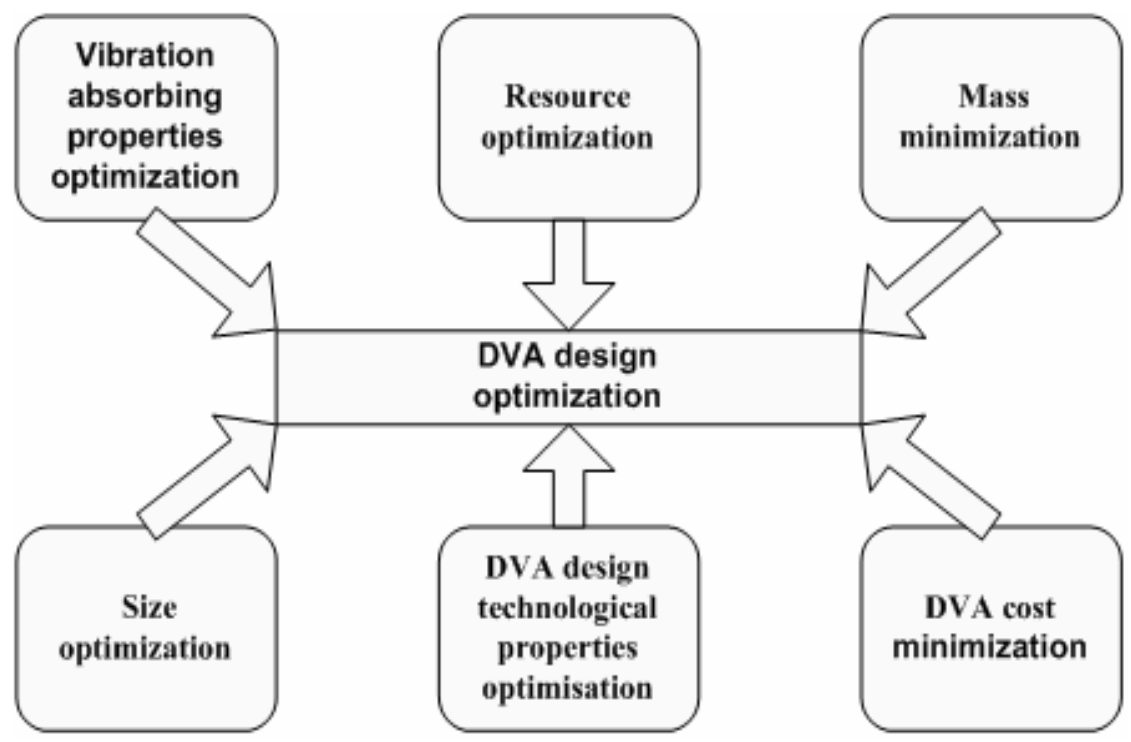

Fig. 3. Diagram of optimization of DVA construction

The most important is criterion of vibration absorbing (Fig. 3). This criterion is very voluminous. It may consist of a vibration protection criterion in some narrow operating frequency range. But, most often, due to the operating conditions of machines, when the prevailing frequency drifts, the first place is the ability of the DVA to operate effectively over a wide range of frequencies. Little attention researchers draw attention to such a question as the durability of the design of the DVA. Elastic elements of the DVA to 
achieve effective vibration absorption should work at maximum amplitudes of oscillations in the zone of maximum permissible stresses.

We can give the following summary parameters of optimal DVA: reliable, versatile, compact, easy to install, wide frequency range, simple control system, low cost, low power consumption.

\section{Types of DVA}

First we will distinguish between passive and active DVA. Unlike active absorbers, the characteristics of passive DVA can not be replaced during its action. This DVA is effective only when there is one specific frequency at which vibration should be reduced. Active DVA can be divided into active and active (semi-active) ones. Active DVA's are characterized by significant energy costs to reduce vibration, roughly speaking, creating an acting force in the antiphase. The semi-active DVA is connected to a controller that uses sensors to analyze vibrations and drives that change the absorber characteristics to reduce vibration not only for a fixed frequency. Thus, the vibrations can be neutralized in a wide spectrum of frequencies. This kind of DVA has a clear advantage if the excitation force constantly changes the frequency, or if the resonant frequencies of the system change due to fluctuations in physical and mechanical properties, for example under the influence of temperature. It is also significantly less energyconsuming than purely active DVA.

DVAs differ in ways of absorbing energy. The most well-known is the DVA with a viscoelastic element, or a combination of elastic element and damper. Electromagnetic and electrostrictive processes, in all sorts of DVA with electromagnets, or piezoelements, are also used. Such DVAs usually belong to the class of active ones, because by means of electrical processes it is easier to manage processes.

In purely mechanical DVA, different types of designs are possible. This is a classic DVA on a spring (cylindrical or flat), a DVA of a pendulum type, a DVA with shock masses, with vibration absorbing containers filled with granular material (particle DVA). Energy scattering can occur both due to internal friction, and with the application of friction elements, shock processes in containers, and also between particles in the "particle DVA". As an inertial element, a liquid can be used in the capacity of a particular configuration. An even wider spectrum of DVAs that use electrical processes.

In [20], DVA's are divided into groups: passive, semi-active, active and hybrid (Fig. 4).

\section{$\mathrm{P}$ :sensor a : actuater $\quad \mathrm{C}_{0}:$ controller}

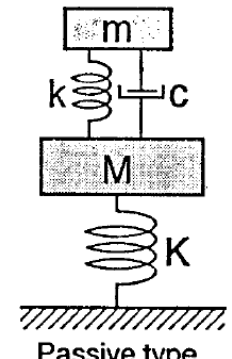

Passive type

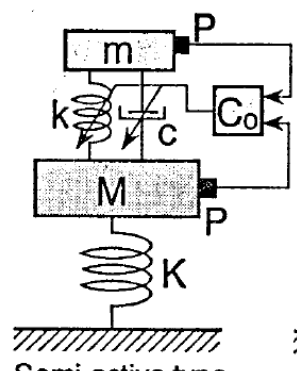

Semi-active type

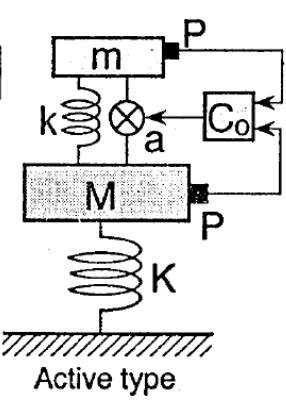

Active type

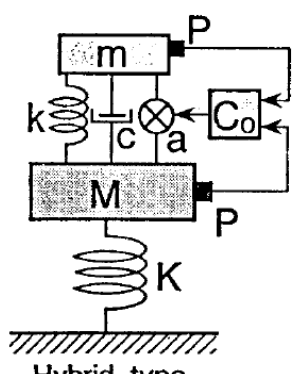

Hybrid type

Fig. 4. Types of DVA

In active DVA's, the quenching of vibrations occurs based on the addition of special energy devices according to a law in time. In fact, this same effect can be achieved without DVA, by influencing the basic object at certain points of energy tides. Significantly lower power consumption of semi-active DVA. In them only elastic and damping parameters are changed in time. In Fig. 5 the diagram of management DVA is given [21]

In managing the dynamics of systems there are many parties that require appropriate technical solutions. In this paper we consider only the simplest methods of controlling semi-active DVA [22]. Different structures of passive DVA are considered in [23-25]. 


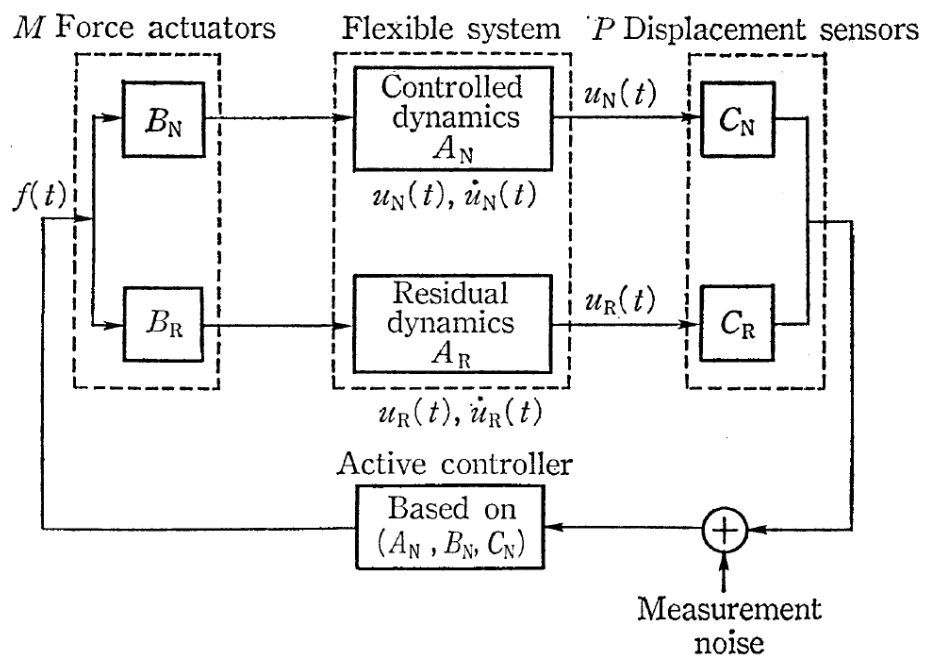

Fig. 5. DVA diagram management

During the last century, because of the important role of DVA in vibration attenuation, many studies have been conducted to evaluate the performance of the absorbers as passive, active and semi-active countermeasures [26]. As structures like bridges, wide-spanned floors, tribunes and high-rise buildings, generally, possess low structural frequencies and little damping, many of these structures originally exhibit medium to high vibration levels. Consequently, the application of DVA's is effective in improving their dynamic performance [27]. The application of largest DVA in the world (660 tons) in the second tallest skyscraper in the world at Taipei 101 [28] (Fig. 6), utilization of eight horizontal and fifty vertical DVA's in Millennium bridge in London [29] and the installation of a 140 tones pendulum absorber in Doha sport city tower in Qatar [30] can be named as some of the most prominent and spectacular usage of DVA's.
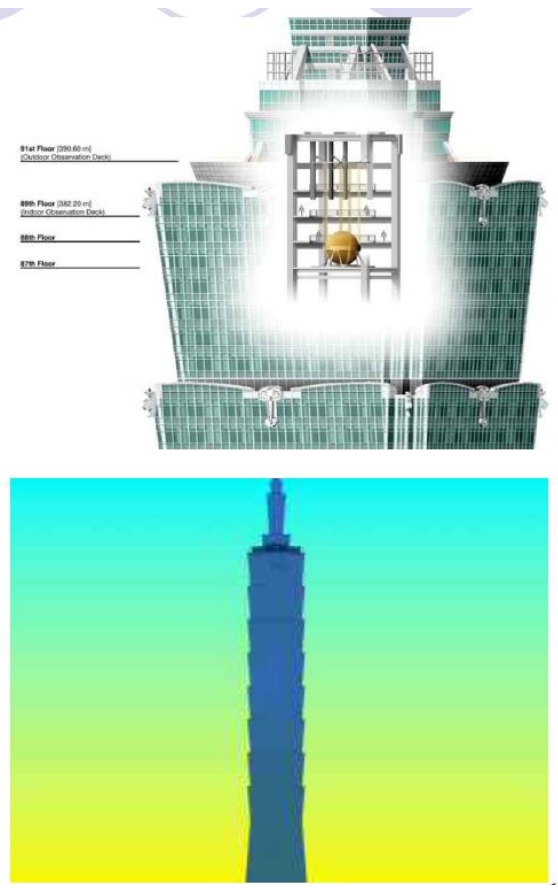
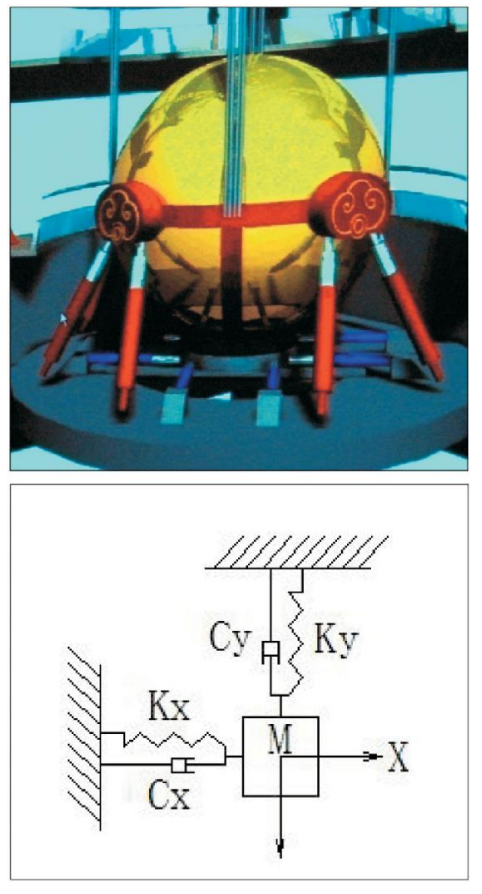

$b$

Fig. 6. The DVA installed in Taipei 101 Tower (a); mechanical model of the DVA in Taipei 101 Tower (b)

In [31] excessive vibrations of a pre-heater tower of a cement factory have been reduced to acceptable levels successfully. This has been achieved by using 2D-damped vibration absorber system functioning in two directions simultaneously (Fig. 7). 


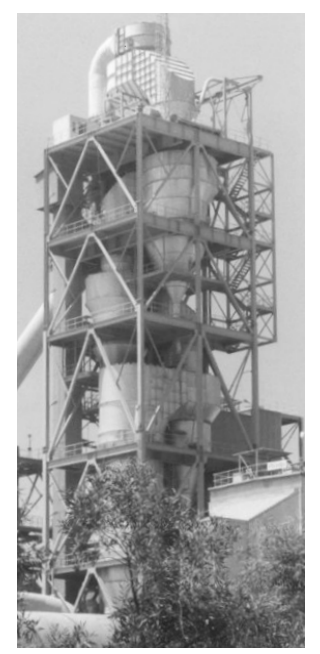

$a$

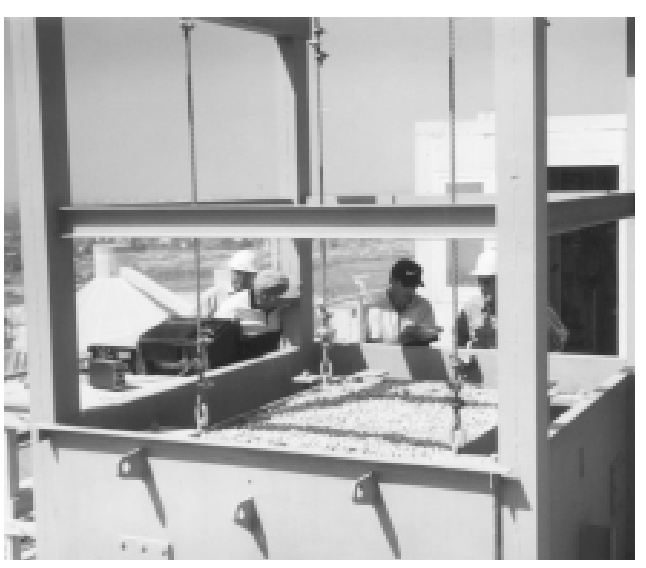

$b$

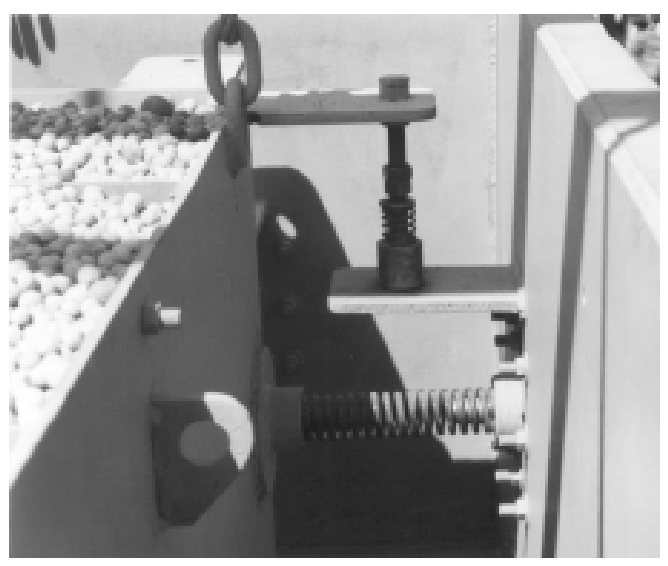

$c$

Fig. 7. The pre-heater tower (a); Overall view of the 2D-vibration absorber (b); Spring and friction damper connections $(c)$

Thus it was possible to increase the nominal production rate by $8 \%$ while keeping the vibrations at acceptable levels, similar to that of other towers operating without any problem. At the time of writing this paper, the 2D-vibration absorber has been functioning satisfactorily for the last 8 months.

\section{Design schemes of structures with DVA}

The DVA design, apparently, was first proposed in [31] in 1911. His name is called tanks to reduce the ship's fluctuations. However, the first recollection of the use of DVA to reduce the ship's fluctuations, as noted in [32], is still found in work [34].

For the first time, the theory of DVA was proposed in [35] In [36] optimal values for frequency and damping in DVA are obtained. The most well-known DVA equations are in [36] and [37].

In both of these books, the theory of DVA is considered in the section: systems with two degrees of freedom. If in [36] after several introductory paragraphs of one example and electromechanical analogy immediately passes to the DVA, then in [37], at first, several examples are considered, including a double physical pendulum, a model of the crew, and a rotor on an elastic basis. In [37], systems without and with damping are sequentially considered. In [36], this has already been done directly for DVA, although, since the equations are identical, there is no fundamental difference. In [36], a non-dimmed DVA is placed in a separate unit, which analyzes its resonant frequencies. In the next section in [36] the damaged DVA is considered. In [36], DVA is not allocated in a separate section at all. But let us consider and compare the main results of [36] and [37]. To describe the fluctuations of the DVA in [36] and [37], the same system of equations is written out:

$$
\begin{gathered}
m_{1} \frac{d^{2} x_{1}}{d t^{2}}+k_{1} x_{1}-k_{2}\left(x_{2}-x_{1}\right)-c\left(\frac{d x_{2}}{d t}-\frac{d x_{1}}{d t}\right)=P \cos (\omega t), \\
m_{2} \frac{d^{2} x_{2}}{d t^{2}}+k_{2}\left(x_{2}-x_{1}\right)+c\left(\frac{d x_{2}}{d t}-\frac{d x_{1}}{d t}\right)=0 .
\end{gathered}
$$

Then in [36] the equations of stable oscillations are written

$$
\begin{gathered}
-\omega^{2} m_{1} u_{1}+k_{1} u_{1}+k_{2}\left(u_{1}-u_{2}+i \omega c\left(u_{1}-u_{2}\right)\right)=P, \\
-\omega^{2} m_{2} u_{2}-k_{2}\left(u_{1}-u_{2}+i \omega c\left(u_{1}-u_{2}\right)\right)=0 .
\end{gathered}
$$

In [36] the solution of the system of algebraic equations (2) is obtained, the same solution is given in [37]. Here is a well-known figure (Fig. 8) for the frequency response of the base, depending on the parameters of the DVA. 


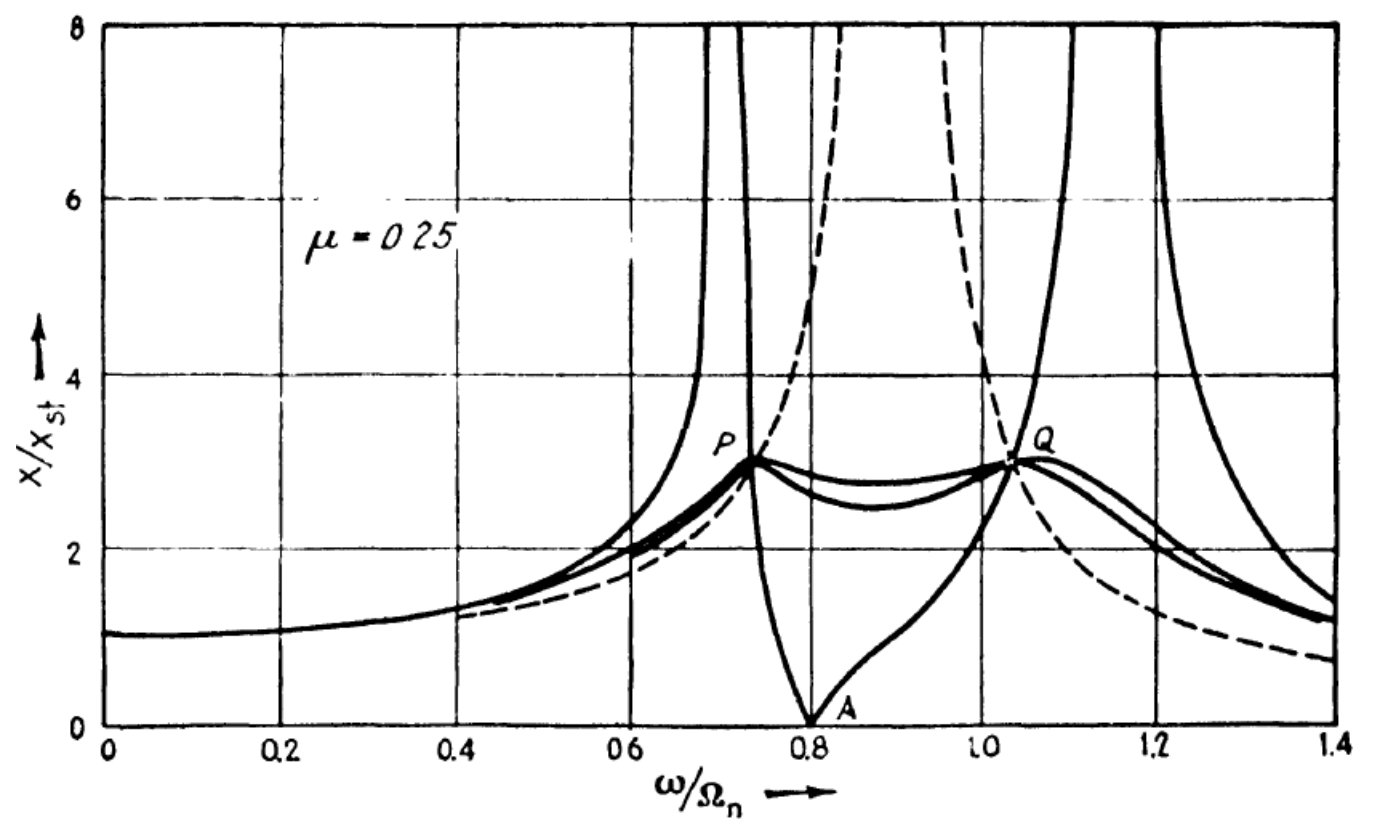

Fig. 8. ACHS basis, depending on the parameters DVA

And in [36] and [37] the conditions of optimality of DVA are obtained. The condition of the same height of the points of the intersection $\mathrm{P}$ and $\mathrm{Q}$ gives such a simple condition

$$
f=1 / 1+\mu, \quad \text { where } \mu=m_{2} / m_{1} .
$$

In [36], the condition of the maximum horizontal line of PQ is found to be approximate:

$$
c=\sqrt{3 \mu / 8(1+\mu)^{3}} \text {. }
$$

In Fig. 7 one optimal curve has a horizontal tangent at the point $\mathrm{P}$ and the other at point $\mathrm{Q}$. The damping values for these curves are somewhat different, and the value (8) is the average of these values. Recall that all these results relate to the idealized case: zero damping in the basis. Only in this case all the curves of the FRF's pass through two points. In the presence of damping, the basis of this will not be. In this paper, this is a more realistic case, and the results of optimization are given by a numerical method and on the basis of $(7,8)$. We can see that formulas $(7,8)$ are far from optimal for the general case of damaged basis.

A large amount of research on DVA is presented in [38]. Here are found optimal values with variable amplitude. The calculation of DVA in pulsed and random disturbances is considered. Some constructive forms of DVA are considered. The use of DVA to continuum elements such as rods, membranes, plates, membranes has also been investigated. Detailed investigated DVA of the pendulum type for high-rise buildings under wind loads. In [38], it is appropriate to state that, for complex structures with a sparse spectrum, the method of optimization of DVA on the basis of the system (1) of the second degree of freedom can be fully applied.

For calculation and optimization of DVA, a wide range of calculation models (PCs) is used, from the simplest types (1) with harmonic loading to complex discrete-continuum nonlinear models with complex vibration-damaging loads. However, as noted in [37] and in the works of many other authors, it is often possible to distinguish, at a given frequency of perturbation, a certain prevailing vibration mode (whose resonant frequency is close to the perturbation frequency) and reduce the problem to (1). For various types of complex perturbations, mainly (1) is studied with an arbitrary right part. Influence on the NS and the types of physical processes that are used and the inertial element itself, which can be both solid and liquid, and in recent times the popularity has gained granular material, which allows you to significantly increase the resource to simplify its design of DVA and significantly increase its resource. Different types of DVA are described in [39]. 
The problem of attaching DVA to a discrete multi-degree-of-freedom or continuous structure has been outlined in many papers and monographs by Bishop and Welbourn [40], Warburton [41], Hunt [25], Snowdon [42], Korenev [38] and Aida et al. [43] to name but a few. Nonlinear DVA have been investigated by Kolovsky [44], Kauderer [45], Pipes [46], Roberson [47]. The article [48] of Ibrahim presents a comprehensive assessment of nonlinear DVA's in the absence of active control means.

In [49] an improved scheme is proposed for identifying the time of contact and calculation of the state variables after impact. This scheme avoids false detection of collisions and embodies collisions or contacts with infinitesimally small differences in velocities. Detailed experiments with a horizontal impact damper explain in [49] the general performance and the resonance vibration of the integrated system, which occurs at a frequency, which is different from the original resonance frequency.

An impact damping system can overcome some limitations by impact as the damping medium and impact mass interaction as the damping mechanism. The paper contemplates the provision of DVA or any number of such absorbers. Such originally designed absorbers reduce vibration selectively in maximum vibration mode without introducing vibration in other modes. For example, the final result is achieved by DVA at far less expense compared to the cost needed to replace the machine foundation with a new, sufficiently massive one. In [50-52] the particle DVA's are presented.

In order to determine the optimal parameters of an absorber the need for complete modeling is obvious. Present research has developed a modern prediction and control methodology, based on a complex continuum theory and the application of special frequency characteristics of structures. The numerical schemes (NS) row for the complex vibroexcitated construction and methods of decomposition and the NS synthesis are considered in our paper on the basis of new methods of modal synthesis [53-55].

The DVA designed in accordance with our proposals also has the advantage that it can be constructed such that it has a wide-range vibration absorption property. Such originally designed absorbers reduce vibration selectively in maximum mode of vibration without introducing vibration in other modes.

Similar in a mathematical plan tasks are examined in [56]. Here basic task: maximally effectively to pass energy to the container with details which are processed.

\section{The semi-active DVA}

The semi-active DVA uses control to adjust the device configuration based on the actual structure of the vibration. As is typical for structural control, there are many types of devices and management laws, some of them are more realistic than others of varying degrees of complexity. A considerable number of practical implementations of semi-active DVAs can be found in the literature, some of which are described in [57-61]. A broad description of the control algorithms that can be used to control these devices can be found in [57], which in turn are divided into two groups. Some of them are based on strategies that constantly change the parameters of the DVA in dynamic mode, and the other - on the ON / OFF control strategy. The latter option, though not as impressive as the first one, tends to result in algorithms that are simpler, more realistic, and easier to implement.

For realization of semi-active control various mechanisms for controlling the movement of DVA are offered. The mechanism based on the Magnetorheological (MR) control method has recently gained popularity in the structural control zone [62]. The application of a magnetic field causes changes in the structure of the liquid MR inside the damper, which is used to control the damping force, in these elements. The simplicity of its mechanical functioning is associated with low direct constructive costs and low running costs for their operation. DVA can simultaneously reduce amplitude of oscillations at several frequencies. In [63], based on the optimal control theory, it has been found that a semi-active DVA can extinguish the vibration of the primary in both the transient and in steady-state modes. In [64], is proposed to suppress the transient vibrations of rotary machines during start-up and stop. In [65, 66] a semi-active vibration absorber with piecewise linear elastic components is presented, which may have an adjustable the operating frequency, which follows the frequency variation of the excitation. In [67] numerically studied two kinds semi-active skyhook DVA, and then magnetic resonator (MR) damper is tapped and experimentally confirmed the improved control efficiency. 


\section{Optimization Algorithms}

Wide application for optimization found algorithms of random search, namely genetic algorithms [68]. The problem of solving such problems is the direction in the computer sciences, which is called Artificial Intelligence. For application of GA mathematical models should adequately reproduce the real dynamic processes in machines and structures with DVA. They must satisfy the following basic requirements: 1) adequate reproduction of dynamic processes in structures; 2) to include in the set of calculation parameters the determining design and technological parameters; 3 ) to be adapted to the next algorithmization and transformation into machine codes (there is somewhat absurd idea that designs should be designed not only on the basis of their functional characteristics, but also on the requirements of their maximum simplification, from the conditions of their simplest mathematical modeling); 4) interact with known software application packages of computer design and computer-based production training; 5) have an information correlation with world-wide patent knowledge bases (for example, from espacenet.com) and with accessible "open" software on the Internet. There are concepts of local and global object search.

$\mathrm{GA}$, in fact, originate from the mechanism of evolution in nature, which is called rigorous selection. According to this scheme only the most suitable individuals are stored for the creation of descendants. This contrasts with the soft selection, which offers a probabilistic mechanism to support the ability of individuals to form descendants, despite the possession of its relatively poorer qualities. GA must contain the following components: representation for potential problem solving; method of creating the initial population of potential solutions; an evaluation function that plays the role of an assessment environment for solutions in terms of their suitability; genetic operators that change the set of descendants; the value of different parameters that use GA (population size, probability of application of genetic operators...).

The basic scheme of GA work consists of the following main phases: 1) creating an initial population, applying the genome to each individual, calculation of target vector; 2) the step of evolution building a new generation; 3 ) check the completion criterion, if not completed - switch to 2.

\section{Robust Optimal Design}

The fundamental definition of robust design is described as a product or process is said to be robust when it is insensitive to the effects of sources of variability, even through the sources themselves have not been eliminated [69]. The questions of robustness are discussed in [70] at optimization of DVA. The weighted sum of deviation of the basic design and the gradient module of this deviation as the main criterion is considered. A set of random values of such parameters as mass and stiffness of DVA is used for graphically constructing a shell of optimal AFC with the deviation of parameters. In our optimization method, genetic methods are used that give a sequence of points of parameters that coincide with the optimal value. On the basis of intermediate results of calculations, it is possible to construct not shells of plane charts, but map parameters, which is more informative. For this purpose, one or two start-ups of the optimization process, preferably with diametrically opposite points of permissible values, prevail. The criterion of robustness is the convexity of these maps in the vicinity of the optimum. It is not a sufficient condition, only necessary. For a more complete study, we introduce the following indicator - the radius of deviation $R_{\Delta}$ :

$$
R_{\Delta}=\min (R), C i L a=(1+\alpha) C i L .
$$

This is the minimum distance from the points with the indicators $(1+\alpha)$ at the higher (worst) points from the optimal point. For optimization in a linear case, only two parameters are depicted in Fig. 8 for $\alpha=2$. In this case, this condition is also sufficient. In the case of a lot of parametric optimization, the convexity of all maps across all parameters pairs is a necessary, but not sufficient condition. In a multidimensional space, the behavior of the target function can be complex. However, the criterion that finds the nearest point with some deviation of the point to the optimum remains effective. For optimization in a linear case only for two parameters (frequency and damping) are depicted in Fig. 9 for $\alpha=2$. 


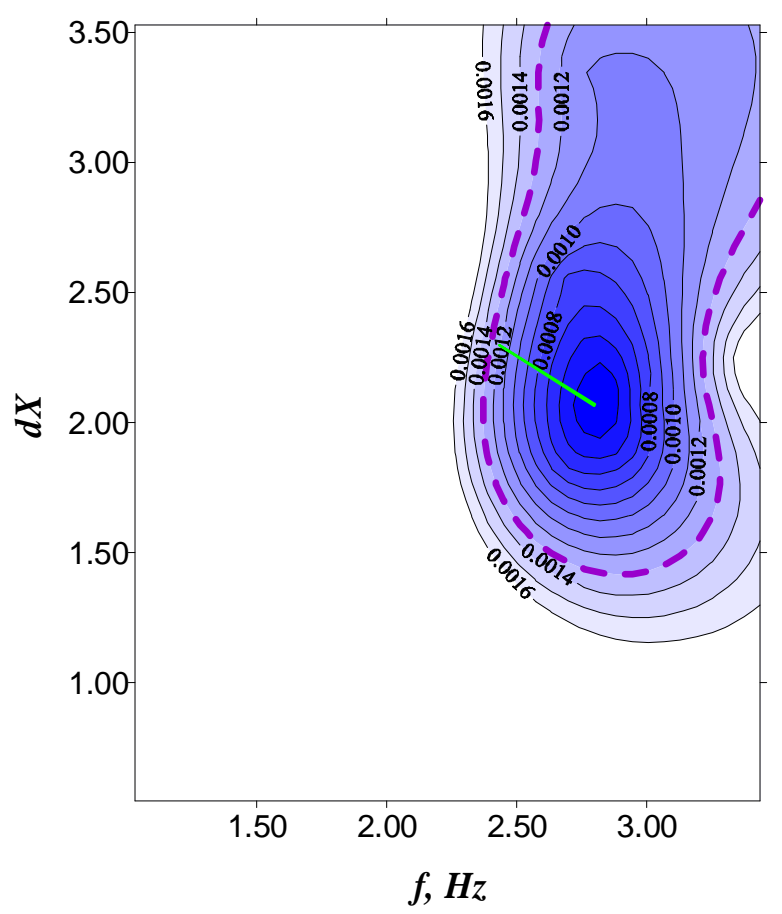

Fig. 9. Map of optimization by two parameters, and the indicator of robustness

\section{DVA modeling}

Consider the frequency response and vibrograms of uncontrolled and controlled damping of DVA (Fig. 10). DVAs come in different types.

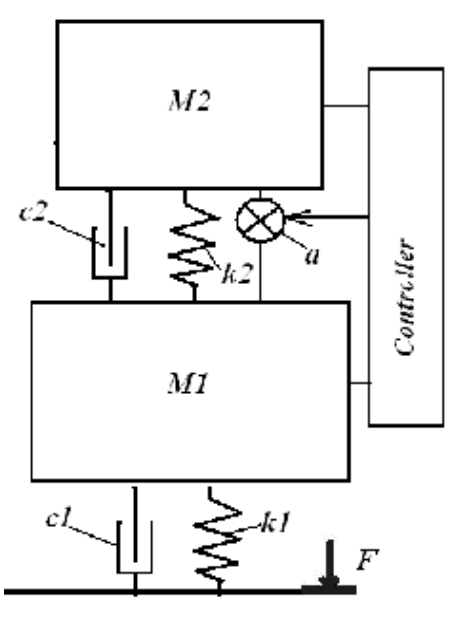

$a$

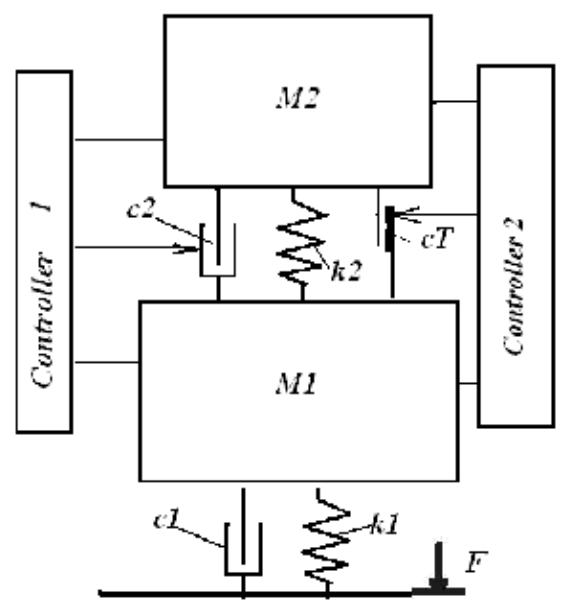

$b$

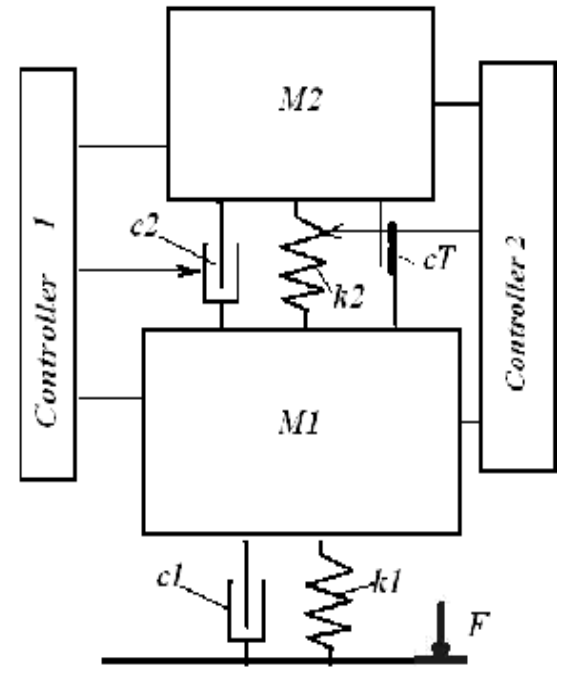

$c$

Fig. 10. Different types of DVA's: $(a)$ - active, $(b)$ - damping and friction control, $(c)$ - rigidity control

Consider the semi-active DVA (Fig. 10,a). This is a DVA with controlled damping elements The DVA equations in this case will be:

$$
\begin{gathered}
m_{1} \frac{d^{2} x_{1}}{d t^{2}}+k_{1} x_{1}+c_{1} \frac{d x_{1}}{d t}-k_{2}\left(x_{2}-x_{1}\right)-c_{2}\left(\frac{d x_{2}}{d t}-\frac{d x_{1}}{d t}\right)-c_{t 2} \operatorname{sign}\left(\frac{d x_{2}}{d t}-\frac{d x_{1}}{d t}\right)=k_{1} x_{0}+c_{1} \frac{d x_{0}}{d t} \\
m_{2} \frac{d^{2} x_{2}}{d t^{2}}+k_{2}\left(x_{2}-x_{1}\right)+c_{2}\left(\frac{d x_{2}}{d t}-\frac{d x_{1}}{d t}\right)+c_{t 2} \operatorname{sign}\left(\frac{d x_{2}}{d t}-\frac{d x_{1}}{d t}\right)=0 .
\end{gathered}
$$


Here a kinematic perturbation with a certain frequency is considered. The coefficients are now variables in time and change according to some rules with the help of controllers (Fig. 10, a). Here the rule [21] for viscous friction is applied

$$
\begin{aligned}
& \operatorname{sign}\left(x_{1}\left(\frac{d x_{2}}{d t}-\frac{d x_{1}}{d t}\right)\right)>0 \quad c_{2}=c_{2 A} ; \\
& \operatorname{sign}\left(x_{1}\left(\frac{d x_{2}}{d t}-\frac{d x_{1}}{d t}\right)\right) \leq 0 \quad c_{2}=c_{2 B} .
\end{aligned}
$$

For optimization the target function is proposed

$$
F_{C I L}=\max \left(\ddot{x_{1}}(f)\right), f_{1}<\mathrm{f}<f_{2} .
$$

Genetic Algorithms (GA) has proven to be a suitable optimization tool for a wide selection of problems [68]. In Fig. 11 the results of optimization for DVA with constant and controlled damping are shown.
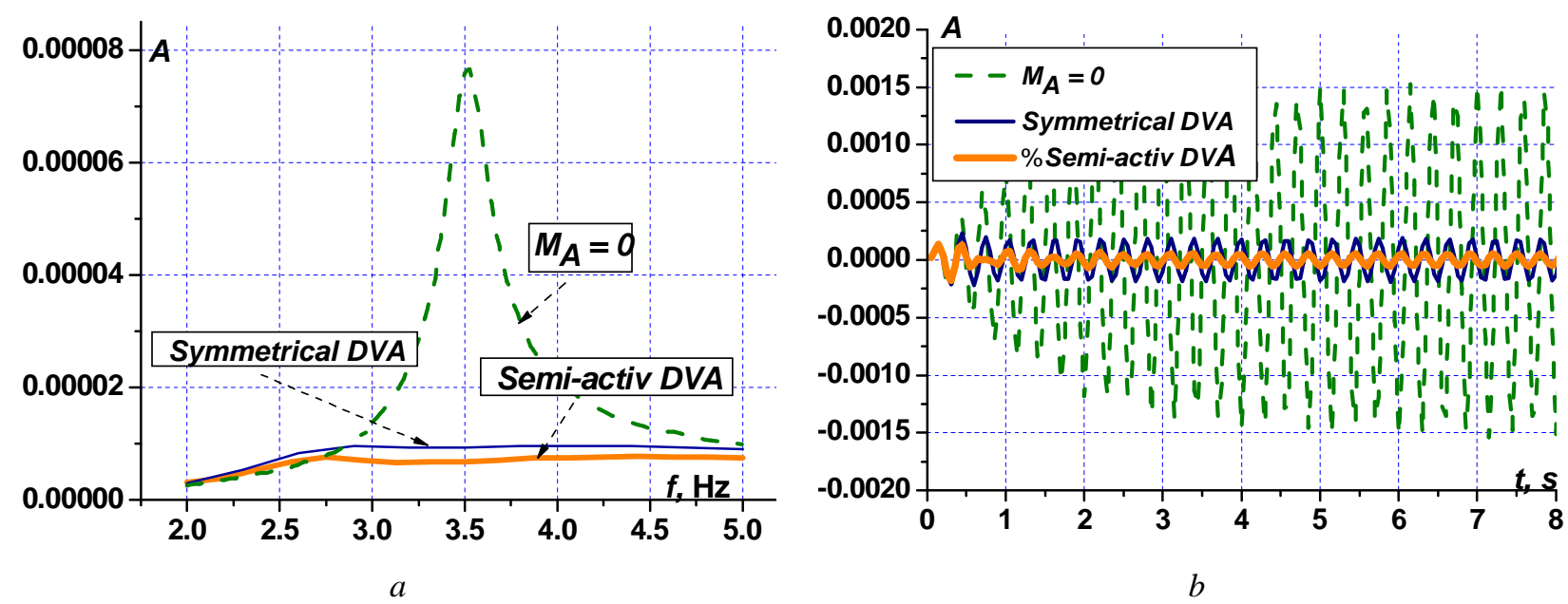

Fig. 11. Results of optimization of the frequency response for DVA with constant damping and controlled damping (a); the corresponding vibration for the frequency inside the optimization interval ( $b$ )

Just as a viscous friction, consider a variable dry friction. The results of optimization for DVA with constant damping and controlled are shown

$$
\begin{aligned}
& \operatorname{sign}\left(x_{1}\left(\frac{d x_{2}}{d t}-\frac{d x_{1}}{d t}\right)\right)>0 \quad c_{t 2}=c_{T 2 A} ; \\
& \operatorname{sign}\left(x_{1}\left(\frac{d x_{2}}{d t}-\frac{d x_{1}}{d t}\right)\right) \leq 0 \quad c_{t 2}=c_{T 2 B} .
\end{aligned}
$$

Fig. 12, $a$, shows optimized FRF for controlled viscous, dry friction and simultaneously controlled these coefficients. Fig. 12, $b$ shows optimized FRF's for DVA driven only by dry friction. Fig. 13 shows optimized FRF's for controlled only by viscous friction.

The optimized FRF's for controlled viscous (active damper), dry (active traction) and simultaneously controlled these coefficients are shown. For comparison, it is indicated by a dashed line of frequency response for a classical DVA. You can notice that due to changes in both viscous and dry friction it is possible to achieve roughly identical results, somewhat better than the classic.

Fig. 14 shows the nature of the change of viscous and dry friction and the difference in mass velocities. In the narrower range, active friction is more effective (Fig. 15).

Here is an improvement in the results. Below (Fig. 16) the map of the target function is shown. 

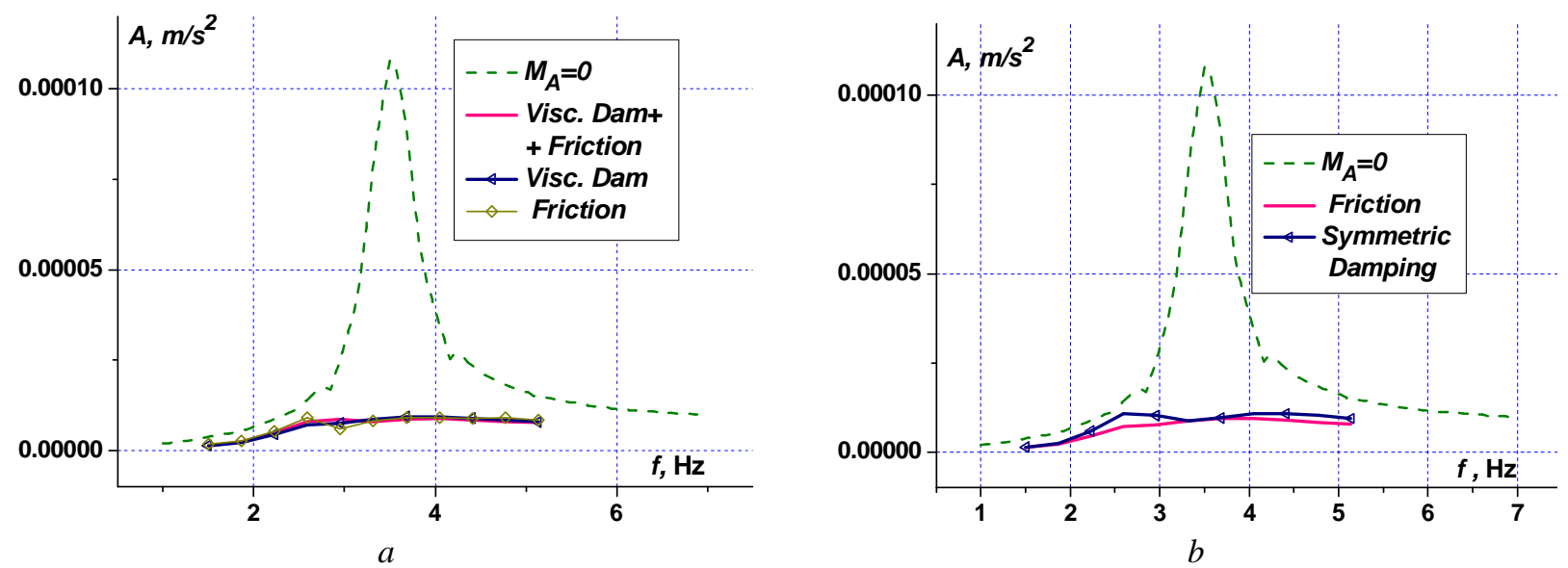

Fig. 12. Optimized FRF's for controlled viscous, dry friction and both controlled simultaneously (a) and optimization results for DVA with permanent damping (Symmetrical DVA) and controlled friction (b)

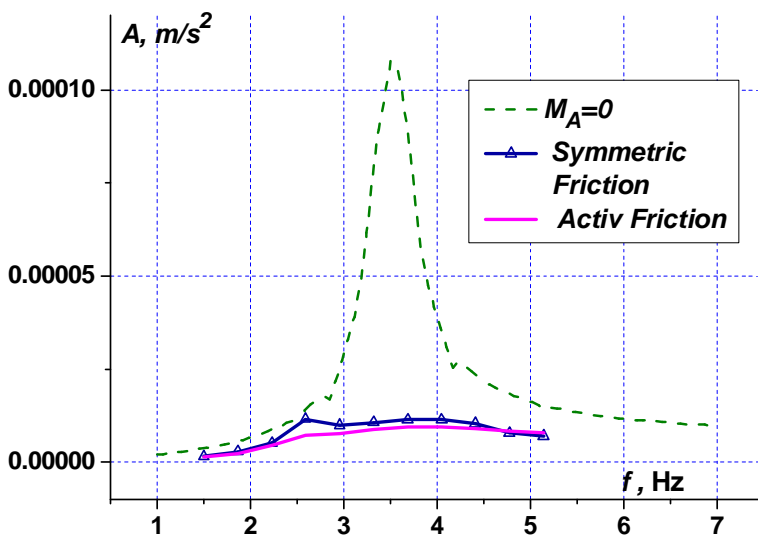

Fig. 13. Results of optimization for DVA with constant andcontrolled viscous friction

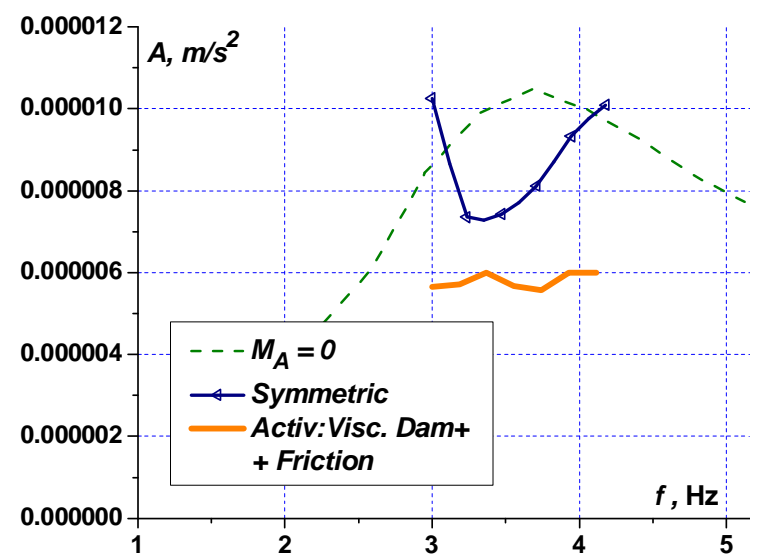

Fig. 15. Narrower range of optimization

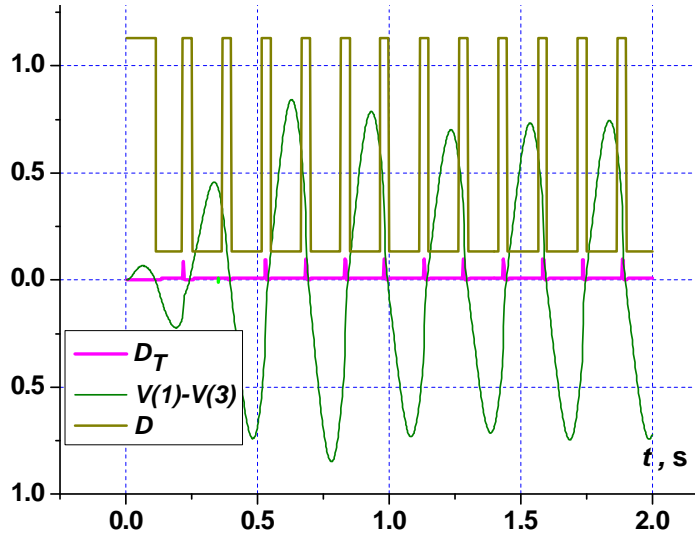

Fig. 14. The nature of change in viscous and dry friction and speed difference

One can notice that here the area of optimal values is significantly narrowed, especially in frequency. As can be seen from the given numerical results, with a wide range of optimizations, controlled damping slightly improves the results. Let's consider now its influence at impulse loading.

\section{Pulse Optimization}

Consider the optimization of the DVA by parameters, with impulse disturbance

$$
C i L=\operatorname{Max}\left(\left|u_{1}(t)\right|\right), t>T_{0} \text {. }
$$


Here, for the target function (14), the maximum deviation of the amplitude of the basis is taken after some initial period of time. Fig. 17 shows optimization with different pulse shapes. Figs. 18, 19 show the results of optimization in the control of viscous and dry friction and without control. Significant influence of damping control is revealed. Figs. 20, 21 show the corresponding maps (for a wider impulse).

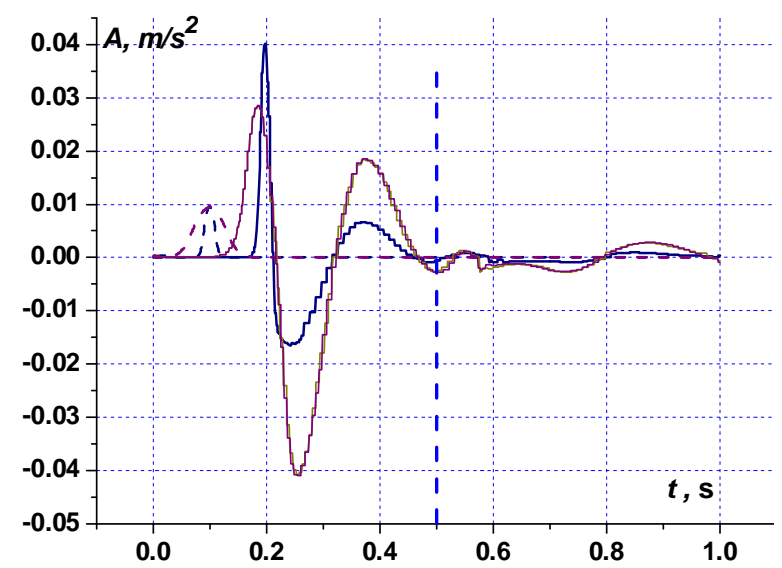

Fig. 17. Results of optimization by different impulse length

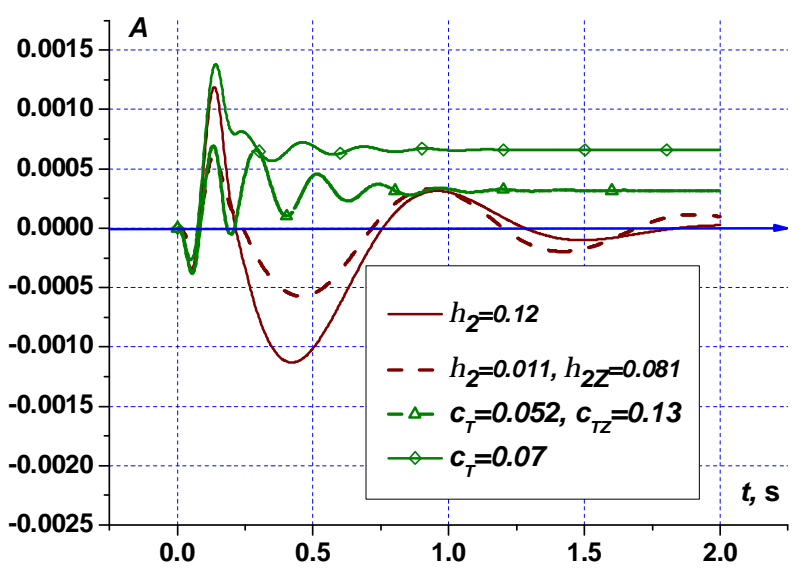

Fig. 19. Optimization results in the management of viscous and dry friction and without control

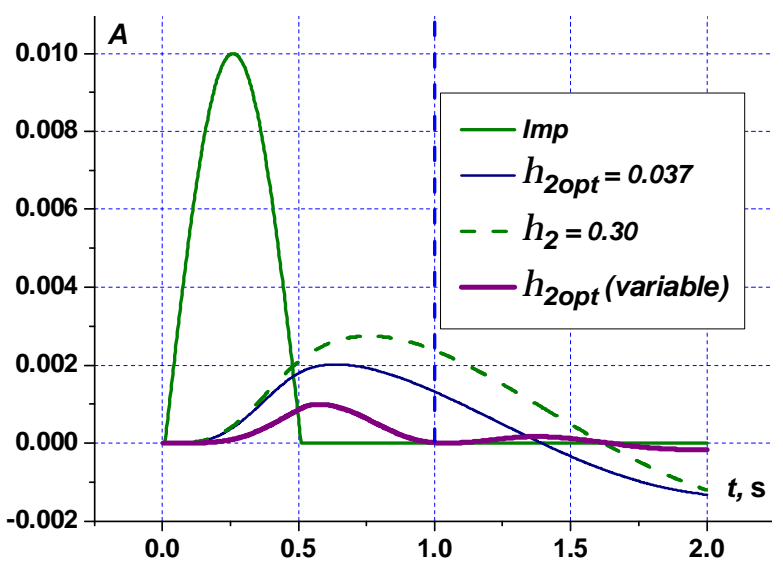

Fig. 18. Results of optimization in the control of viscous friction and without control

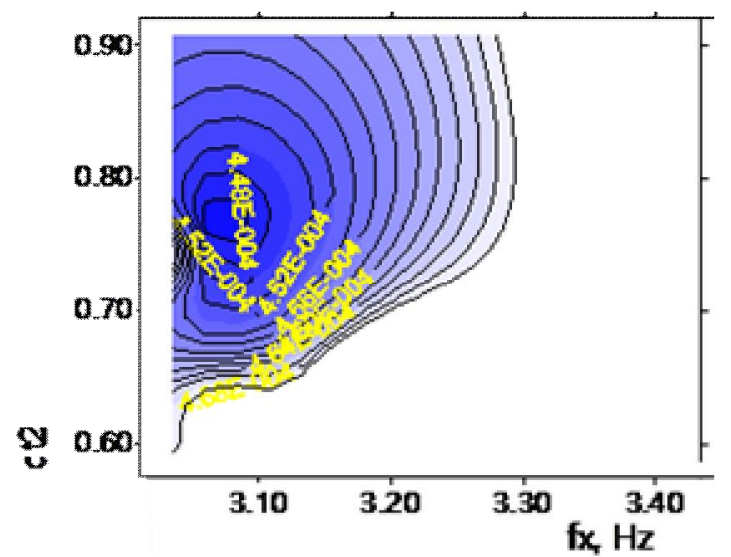

Fig. 20. Map of the target function in frequency and dry friction

Optimizing viscous friction (0.00028) is almost twice as effective as optimizing for dry friction (0.000448), but less robust (see the map in Figs. 20, 21). Fig. 22 shows the advantage of controlled DVA.

The use of controlled DVA improves the result by 2 times. Consider the DVA scheme with controlled frequency and damping (Fig. 10, c). Fig. 23 shows the DVA frequency control and damping frequency. Fig. 24 shows the DVA with controlled damping and no control in frequency.

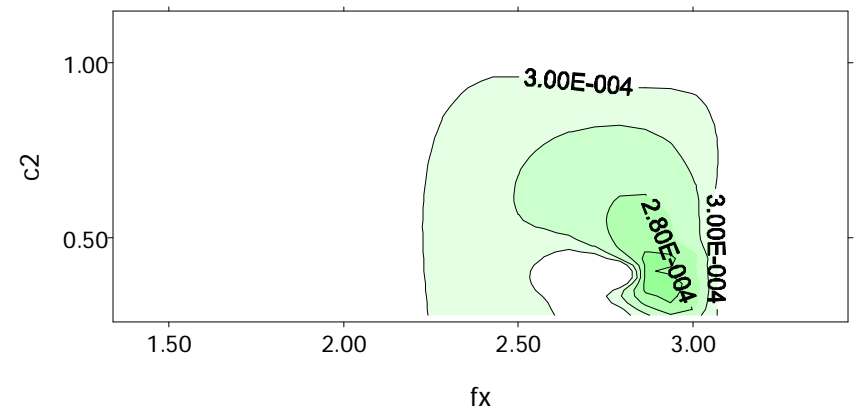

Fig. 21. Map of the target function in frequency and viscous friction 

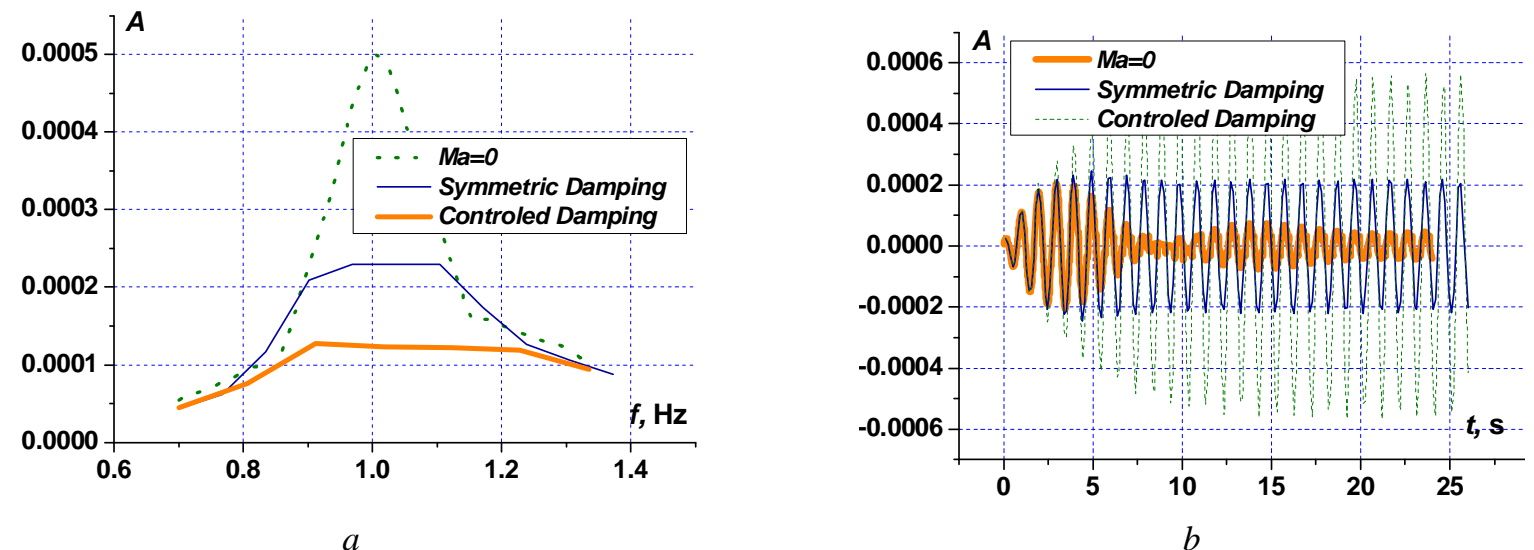

Fig. 22. Controlled (a) and uncontrolled (b) DVA
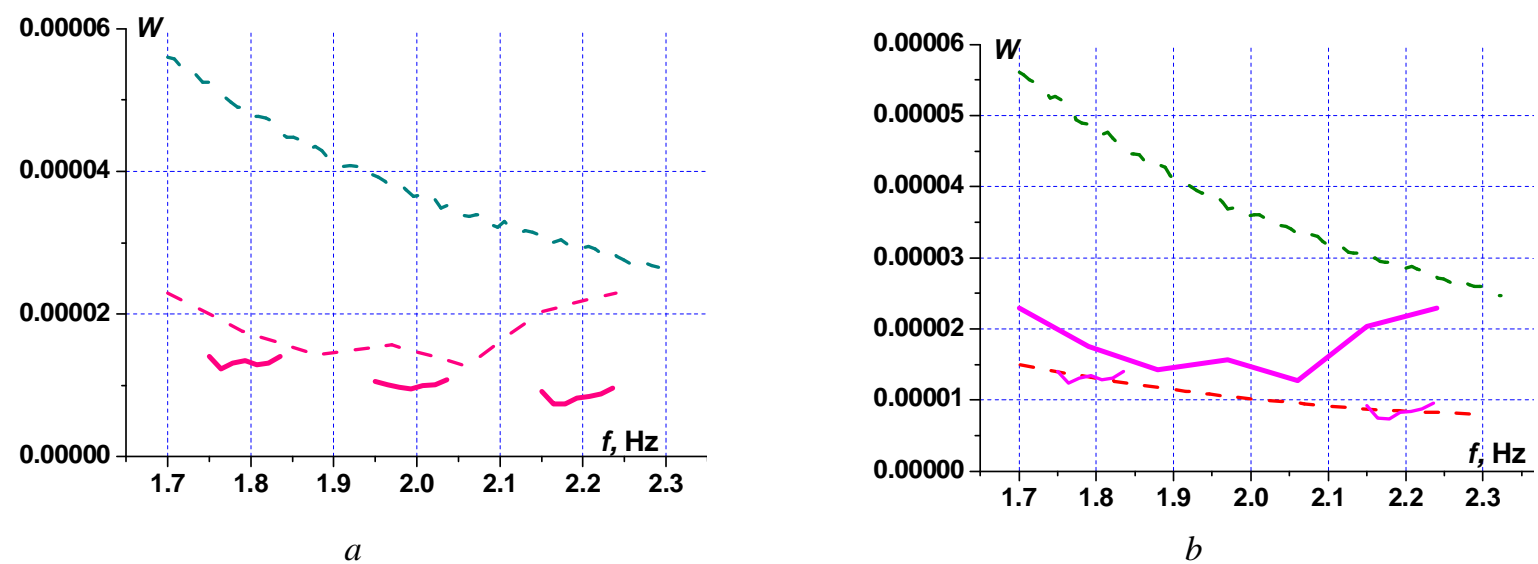

Fig. 23. DVA frequency controlled and frequency controlled dampers

The table 1 shows optimal values for DVA parameters. One can notice the positive role of control both in frequency and in damping in DVA.

Table 1

Optimal Values for DVA Parameters

\begin{tabular}{|c|c|c|c|}
\hline $2.25 \mathrm{~Hz}>f>1.7 \mathrm{~Hz}$ & $1.85 \mathrm{~Hz}>f>1.75 \mathrm{~Hz}$ & $2.05 \mathrm{~Hz}>f>1.95 \mathrm{~Hz}$ & $2.25 \mathrm{~Hz}>f>2.15 \mathrm{~Hz}$ \\
\hline$\eta_{A m}=3.55$ & $\eta_{A m}=0.852$ & $\eta_{A m}=0.675$ & $\eta_{A m}=0.493$ \\
\hline$f=2.0 \mathrm{~Hz}$ & $f=1.81 \mathrm{~Hz}$ & $f=2.2 \mathrm{~Hz}$ & $f=2.22 \mathrm{~Hz}$ \\
\hline
\end{tabular}

\section{Different Types of Control Management}

Different types of control are known. Continuous control of DVA parameters is used.

$$
\begin{gathered}
m_{1} \frac{d^{2} x_{1}}{d t^{2}}+k_{1} x_{1}+c_{1} \frac{d x_{1}}{d t}-k_{2}\left(x_{2}-x_{1}\right)-c_{2}\left(\frac{d x_{2}}{d t}-\frac{d x_{1}}{d t}\right)-F(t)=k_{1} x_{0}+c_{1} \frac{d x_{0}}{d t} \\
m_{2} \frac{d^{2} x_{2}}{d t^{2}}+k_{2}\left(x_{2}-x_{1}\right)+c_{2}\left(\frac{d x_{2}}{d t}-\frac{d x_{1}}{d t}\right)+F(t)=0 .
\end{gathered}
$$

Here control is a function $F(t)$. Consider some simple control algorithms. This is, first of all, The rule (11) is known as sky-hook, or on-off [57-69] for viscous friction. The effectiveness of this rule in the wide-frequency range is shown above. But there are similar rules of management $[71,72]$.

$$
\operatorname{sign}\left(\frac{d x_{1}}{d t}\left(\frac{d x_{2}}{d t}-\frac{d x_{1}}{d t}\right)\right)>0 \quad c_{2}=c_{2 A} ; \quad \operatorname{sign}\left(\frac{d x_{1}}{d t}\left(\frac{d x_{2}}{d t}-\frac{d x_{1}}{d t}\right)\right) \leq 0 \quad c_{2}=c_{2 B},
$$


or

$$
\operatorname{sign}\left(\frac{d^{2} x_{1}}{d t^{2}}\left(\frac{d x_{2}}{d t}-\frac{d x_{1}}{d t}\right)\right)>0 \quad c_{2}=c_{2 A} ; \quad \operatorname{sign}\left(\frac{d^{2} x_{1}}{d t^{2}}\left(\frac{d x_{2}}{d t}-\frac{d x_{1}}{d t}\right)\right) \leq 0 \quad c_{2}=c_{2 B} .
$$

The results of applying these rules are shown in Fig. 25. As you can see, the results are much worse.

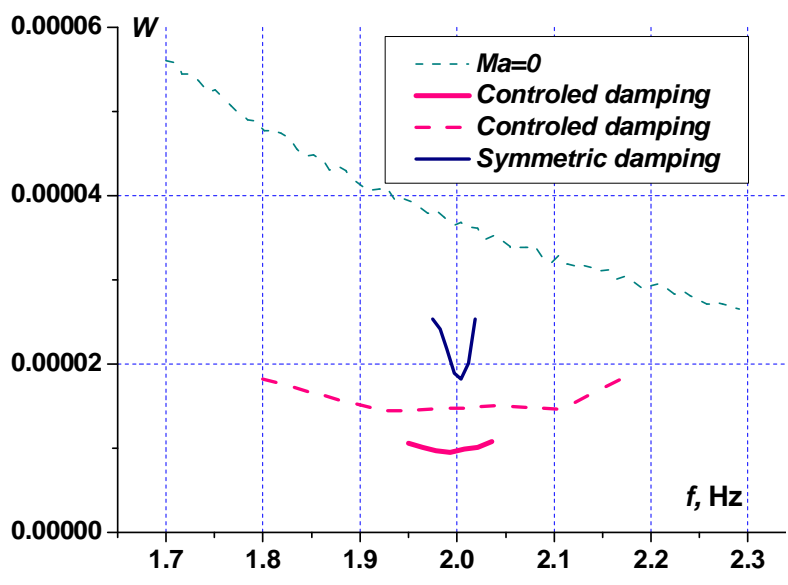

Fig. 24. FRF of DVA with controlled damping and no control in frequency

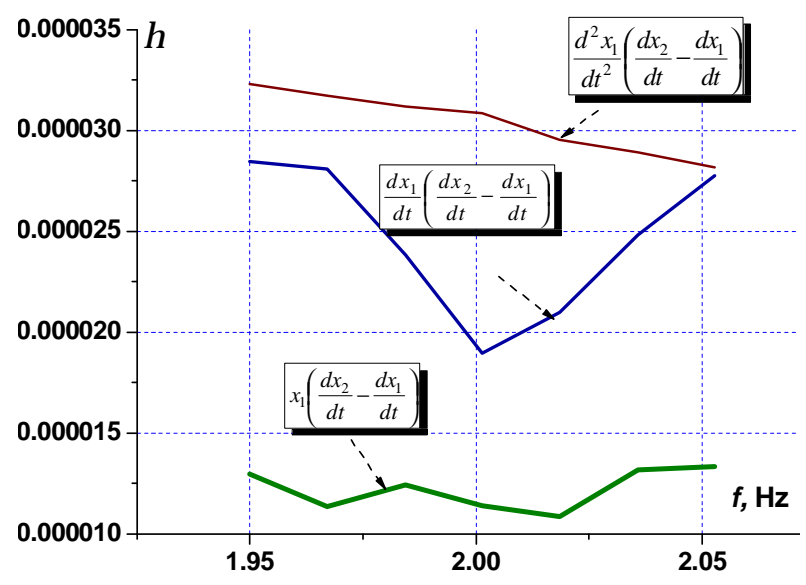

Fig. 25. Results of different rules of damping control in $D V A$

In Fig. 26 the optimal process of oscillation and variable damping for control (17) is shown. Target function was asked in the form

$$
C i L=\operatorname{Max}\left(\left|u_{1}(t)\right|\right), t>T_{0}, T_{0}=30 \mathrm{~s} .
$$

The optimization process is shown in the Table 2.

Table 2

\section{Optimization Process}

\begin{tabular}{c}
$\mathrm{fx} .134 \mathrm{E}+01 \mathrm{dx} .112 \mathrm{E}+00 \mathrm{dx} 2.169 \mathrm{E}-02 \mathrm{k} 1.22 \mathrm{E}-01 \mathrm{k} 2.65 \mathrm{E}+00 \mathrm{CiL} .671 \mathrm{E}-04$ \\
$\mathrm{Mx} .400 \mathrm{E}+01 \mathrm{M} 1.270 \mathrm{E}+03 \mathrm{f} 1.100 \mathrm{E}+01 \mathrm{~d} 1.100 \mathrm{E}-01$ \\
$\mathrm{~N}=2$ \\
\hline $\mathrm{fx} .279 \mathrm{E}+01 \mathrm{dx} .185 \mathrm{E}+00 \mathrm{dx} 2.114 \mathrm{E}-02 \mathrm{k} 1.69 \mathrm{E}-01 \mathrm{k} 2.89 \mathrm{E}+00 \mathrm{CiL} .364 \mathrm{E}-04$ \\
$\mathrm{Mx} .400 \mathrm{E}+01 \mathrm{M} 1.270 \mathrm{E}+03 \mathrm{f} 1.100 \mathrm{E}+01 \mathrm{~d} 1.100 \mathrm{E}-01$ \\
$\mathrm{~N}=12$ \\
\hline $\mathrm{fx} .273 \mathrm{E}+01 \mathrm{dx} .184 \mathrm{E}+00 \mathrm{dx} 2.114 \mathrm{E}-02 \mathrm{k} 1.57 \mathrm{E}-01 \mathrm{k} 2.65 \mathrm{E}+00 \mathrm{CiL} .356 \mathrm{E}-04$ \\
$\mathrm{Mx} .400 \mathrm{E}+01 \mathrm{M} 1.270 \mathrm{E}+03 \mathrm{f} 1.100 \mathrm{E}+01 \mathrm{~d} 1.100 \mathrm{E}-01$ \\
$\mathrm{~N}=63$ \\
$\mathrm{fx} .206 \mathrm{E}+01 \mathrm{dx} .182 \mathrm{E}+00 \mathrm{dx} 2.435 \mathrm{E}-03 \mathrm{k} 1.96 \mathrm{E}-01 \mathrm{k} 2.36 \mathrm{E}-01 \mathrm{CiL} .244 \mathrm{E}-04$ \\
$\mathrm{Mx} .400 \mathrm{E}+01 \mathrm{M} 1.270 \mathrm{E}+03 \mathrm{f} 1.100 \mathrm{E}+01 \mathrm{~d} 1.100 \mathrm{E}-01$ \\
$\mathrm{~N}=66$ \\
$\mathrm{fx} .207 \mathrm{E}+01 \mathrm{dx} .182 \mathrm{E}+00 \mathrm{dx} 2.401 \mathrm{E}-03 \mathrm{k} 1.95 \mathrm{E}-01 \mathrm{k} 2.36 \mathrm{E}-01 \mathrm{CiL} .241 \mathrm{E}-04$ \\
$\mathrm{Mx} .400 \mathrm{E}+01 \mathrm{M} 1.270 \mathrm{E}+03 \mathrm{f} 1.100 \mathrm{E}+01 \mathrm{~d} 1.100 \mathrm{E}-01$ \\
$\mathrm{~N}=112$ \\
$\mathrm{Mx} .400 \mathrm{E}+01 \mathrm{M} 1.270 \mathrm{E}+03 \mathrm{f} 1.100 \mathrm{E}+01 \mathrm{~d} 1.100 \mathrm{E}-01$ \\
$\mathrm{~N}=113$ \\
$\mathrm{fx} .204 \mathrm{E}+01 \mathrm{dx} .158 \mathrm{E}+00 \mathrm{dx} 2.401 \mathrm{E}-03 \mathrm{k} 1.46 \mathrm{E}-01 \mathrm{k} 2.16 \mathrm{E}+00 \mathrm{CiL} .221 \mathrm{E}-04$ \\
$\mathrm{Mx} .400 \mathrm{E}+01 \mathrm{M} 1.270 \mathrm{E}+03 \mathrm{f} 1.100 \mathrm{E}+01 \mathrm{~d} 1.100 \mathrm{E}-01$ \\
$\mathrm{~N}=115$
\end{tabular}


Continuation of the table 2

\begin{tabular}{|}
$\mathrm{fx} .204 \mathrm{E}+01 \mathrm{dx} .158 \mathrm{E}+00 \mathrm{dx} 2.157 \mathrm{E}-03 \mathrm{k} 1.95 \mathrm{E}-01 \mathrm{k} 2.16 \mathrm{E}+00 \mathrm{CiL} .200 \mathrm{E}-04$ \\
$\mathrm{Mx} .400 \mathrm{E}+01 \mathrm{M} 1.270 \mathrm{E}+03 \mathrm{f} 1.100 \mathrm{E}+01 \mathrm{~d} 1.100 \mathrm{E}-01$ \\
$\mathrm{~N}=127$ \\
\hline $\mathrm{fx} .201 \mathrm{E}+01 \mathrm{dx} .152 \mathrm{E}+00 \mathrm{dx} 2.153 \mathrm{E}-03 \mathrm{k} 1.95 \mathrm{E}-01 \mathrm{k} 2.16 \mathrm{E}+00 \mathrm{CiL} .167 \mathrm{E}-04$ \\
$\mathrm{Mx} .400 \mathrm{E}+01 \mathrm{M} 1.270 \mathrm{E}+03 \mathrm{f} 1.100 \mathrm{E}+01 \mathrm{~d} 1.100 \mathrm{E}-01$ \\
$\mathrm{~N}=568$ \\
$\mathrm{fx} .201 \mathrm{E}+01 \mathrm{dx} .158 \mathrm{E}+00 \mathrm{dx} 2.157 \mathrm{E}-03 \mathrm{k} 1.83 \mathrm{E}-01 \mathrm{k} 2.65 \mathrm{E}+00 \mathrm{CiL} .145 \mathrm{E}-04$ \\
$\mathrm{Mx} .400 \mathrm{E}+01 \mathrm{M} 1.270 \mathrm{E}+03 \mathrm{f} 1.100 \mathrm{E}+01 \mathrm{~d} 1.100 \mathrm{E}-01$ \\
$\mathrm{~N}=1067$ \\
$\mathrm{fx} .201 \mathrm{E}+01 \mathrm{dx} .161 \mathrm{E}+00 \mathrm{dx} 2.357 \mathrm{E}-04 \mathrm{k} 1.14 \mathrm{E}+00 \mathrm{k} 2.15 \mathrm{E}+00 \mathrm{CiL} .133 \mathrm{E}-04$ \\
$\mathrm{Mx} .400 \mathrm{E}+01 \mathrm{M} 1.270 \mathrm{E}+03 \mathrm{f} 1.100 \mathrm{E}+01 \mathrm{~d} 1.100 \mathrm{E}-01$
\end{tabular}

Fig. 27 graphically shows the process of frequency optimization and damping (maximal) in DVA.

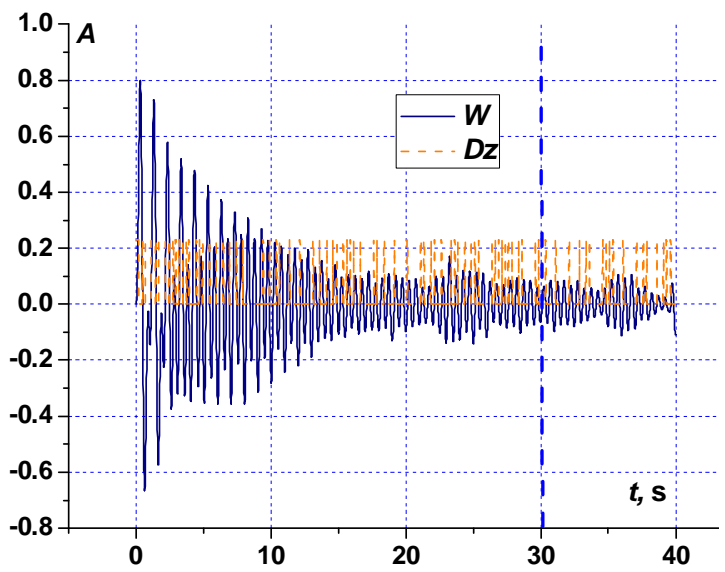

Fig. 26. Optimal process of oscillation and variable damping

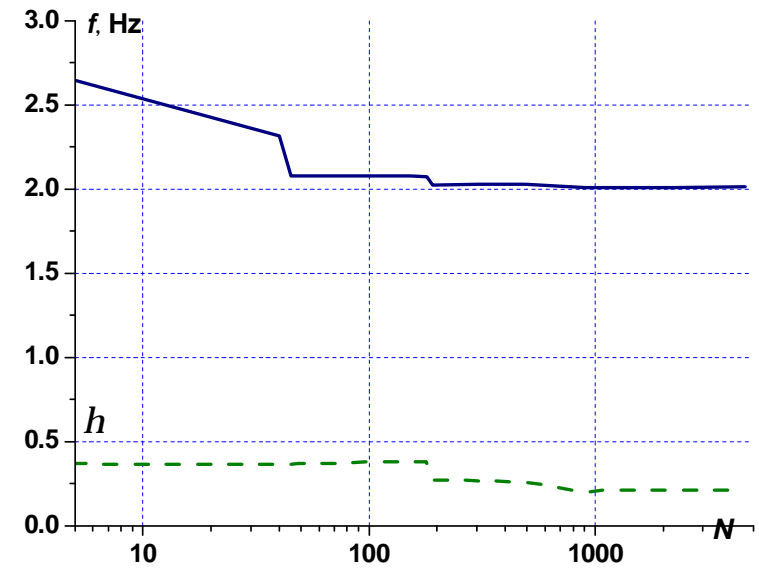

Fig. 27. The process of frequency optimization and damping

In Fig. 28 a map of the target function of frequency and damping in the DVA is shown.

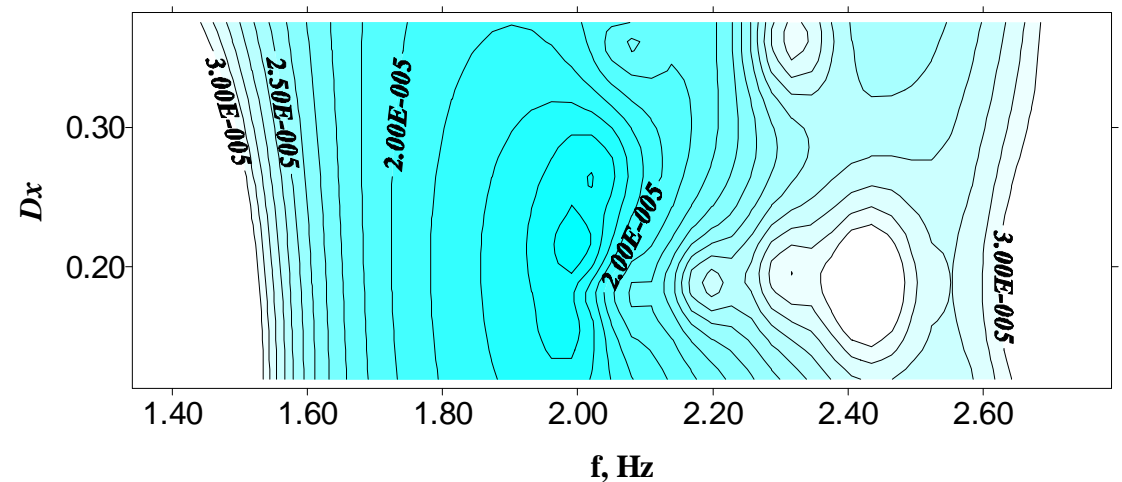

Fig. 28. Target function map for frequency and damping in DVA

Here there is a threatening deterioration of the target function in the vicinity of $2.4 \mathrm{~Hz}$. It should be possible to select the optimal parameters of the DVA slightly shifted to the left, for example, $\mathrm{f}=1.9 \mathrm{~Hz}$.

We shall also investigate the effectiveness of different control rules in the classical case in the vicinity of the resonance (Fig. 29).

Just like outside the resonance zone, ON-OFF control is effective only. Other management is just a bit better than an uncontrollable process. In Fig. 30 the optimal FRF for DVA with different weights are shown with the use of ON-OFF control. 


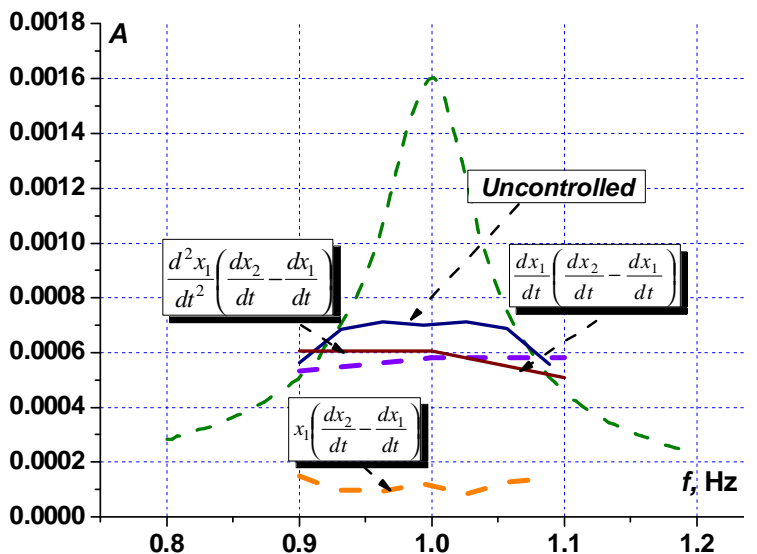

Fig. 29. The effectiveness of different control rules in the vicinity of the resonance

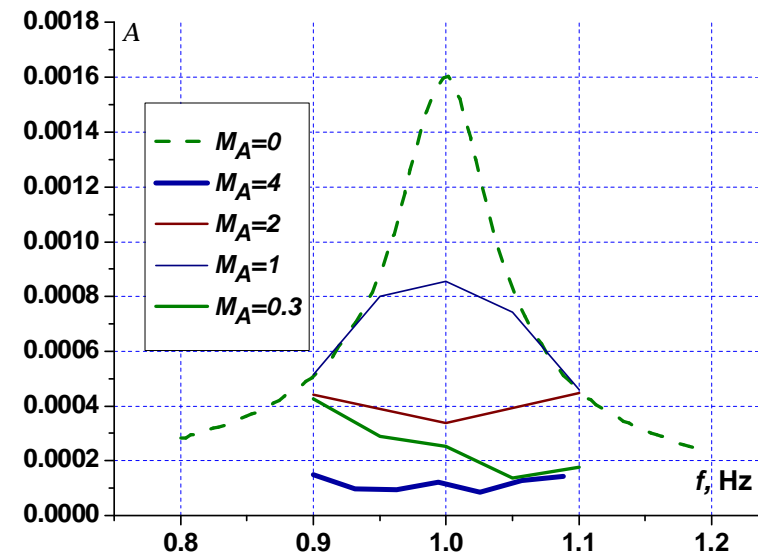

Fig. 30. Optimal AFC for DVA with different weights when using ON-OFF control

\section{Bang-Bang Control}

Let us consider additionally Bang-Bang control.

$$
\operatorname{sign}\left(x_{2} \frac{d x_{2}}{d t}\right)>0 \quad c_{2}=c_{2 A} ; \quad \operatorname{sign}\left(x_{2} \frac{d x_{2}}{d t}\right) \leq 0 \quad c_{2}=c_{2 B} .
$$

This and other control of DVA damping by frequency loading are presented in Fig. 31. In Fig. 32 different control of DVA damping by frequency loading (vibration ad control in time) is presented.

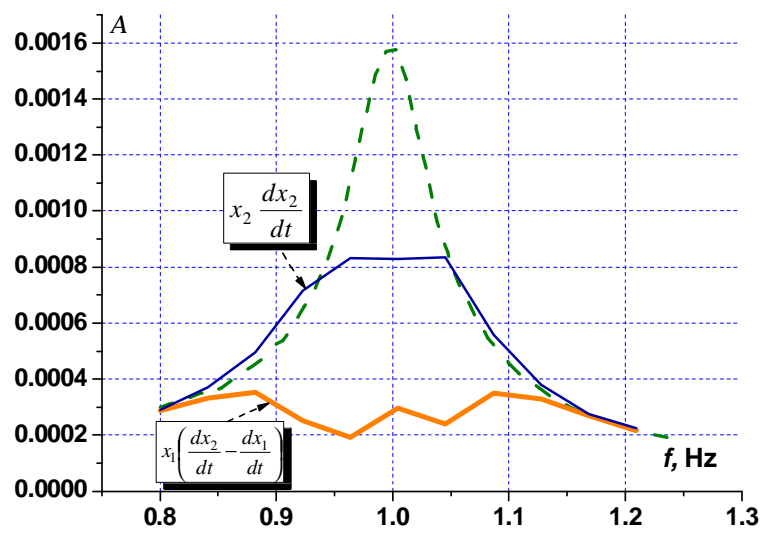

Fig. 31. Different control (ON-OFF and Bang-Bang) of DVA damping by frequency loading

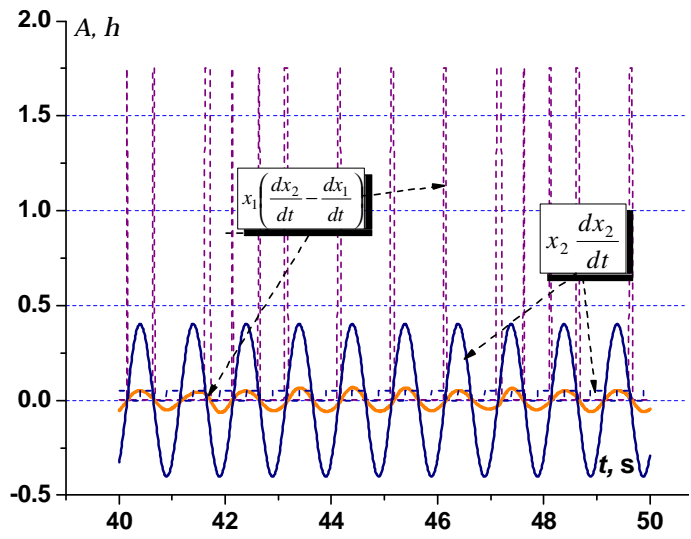

Fig. 32. Different control of DVA damping by frequency loading (vibration ad control in time)

Different control of DVA damping by impact loading are presented in Fig. 33. It can be seen that only ON-OFF (11) controls are effective for both frequency perturbation and pulse loading.

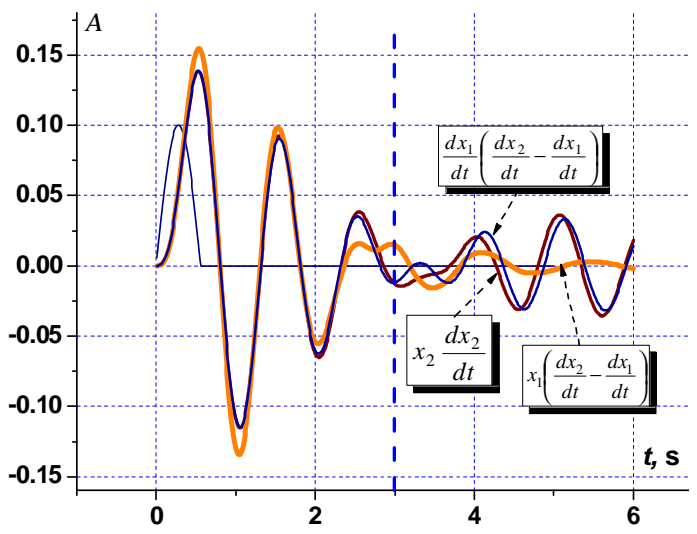

Fig. 33. Different control of DVA damping by impact loading 


\section{Examples of DVA's Practical Implementation}

Let's consider some examples of the use of DVA for large-sized structures and high-rise buildings.

(A) Stabilization of the rod of the boom-sprayer in a horizontal plane. The most important functional feature of sprayers is the rapid and even spraying of drugs to the largest area without passing these drugs beyond the cultivated area. Especially important role is played by the parameters of such functional units as a rod with a suspension for rod sprayers. A special study requires the dynamics of the air mixture propagation directly near the sprayer and at the surface layer of the atmosphere. Appropriate mathematical models are sufficiently developed to study the dynamics of the rod element in the vertical and horizontal plane [75-78]. In rod sprayers, the uniformity of spraying is closely correlated with the fluctuations of the rod relative to the ground surface of the horizontal plane. To reduce the amplitude of these oscillations, consider a boom sprayer with a dynamic vibration damper ([77, 79], Fig. 34). For calculations, a typical five-section bar was considered (Fig. 35, wing rod).

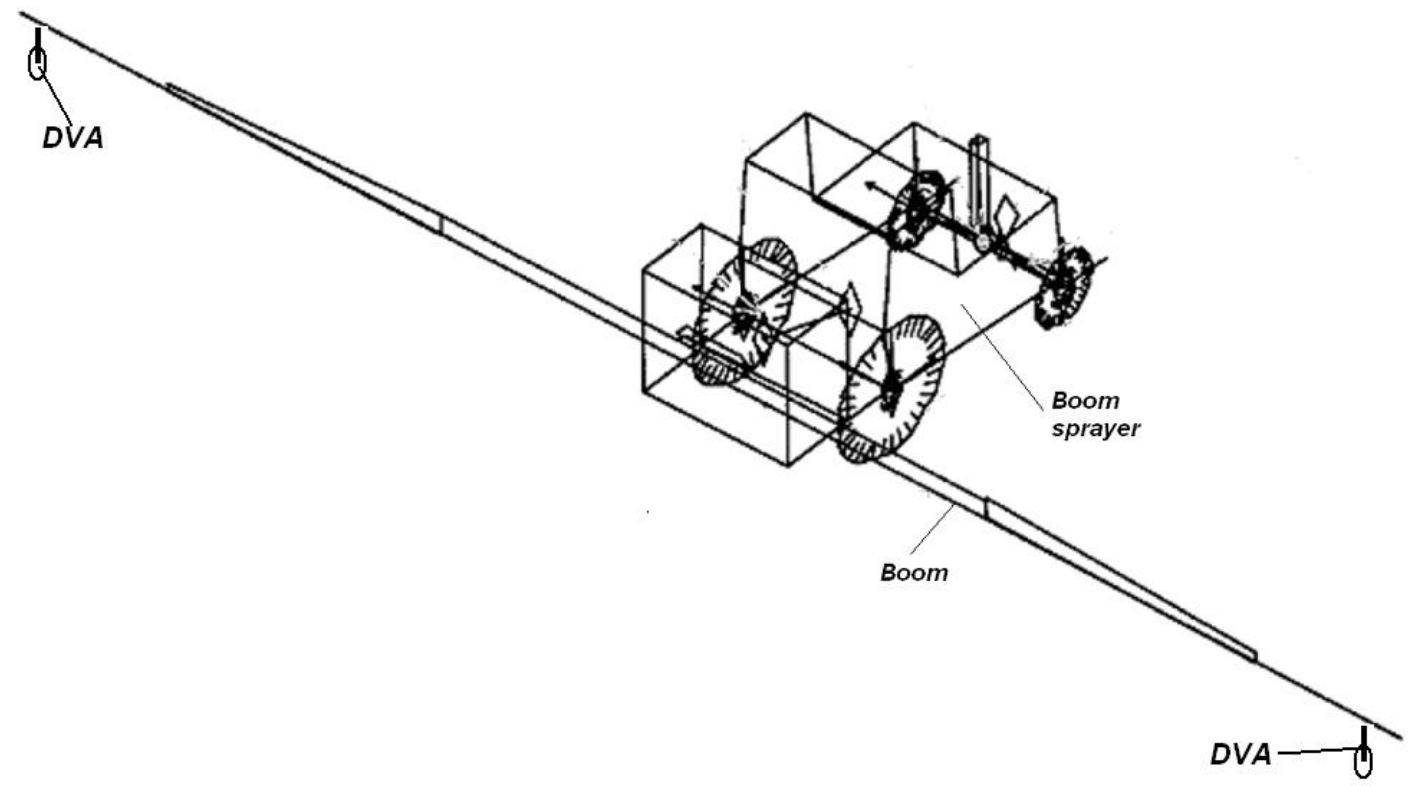

Fig. 34. Different control of DVA damping by frequency loading (vibration ad control in time)

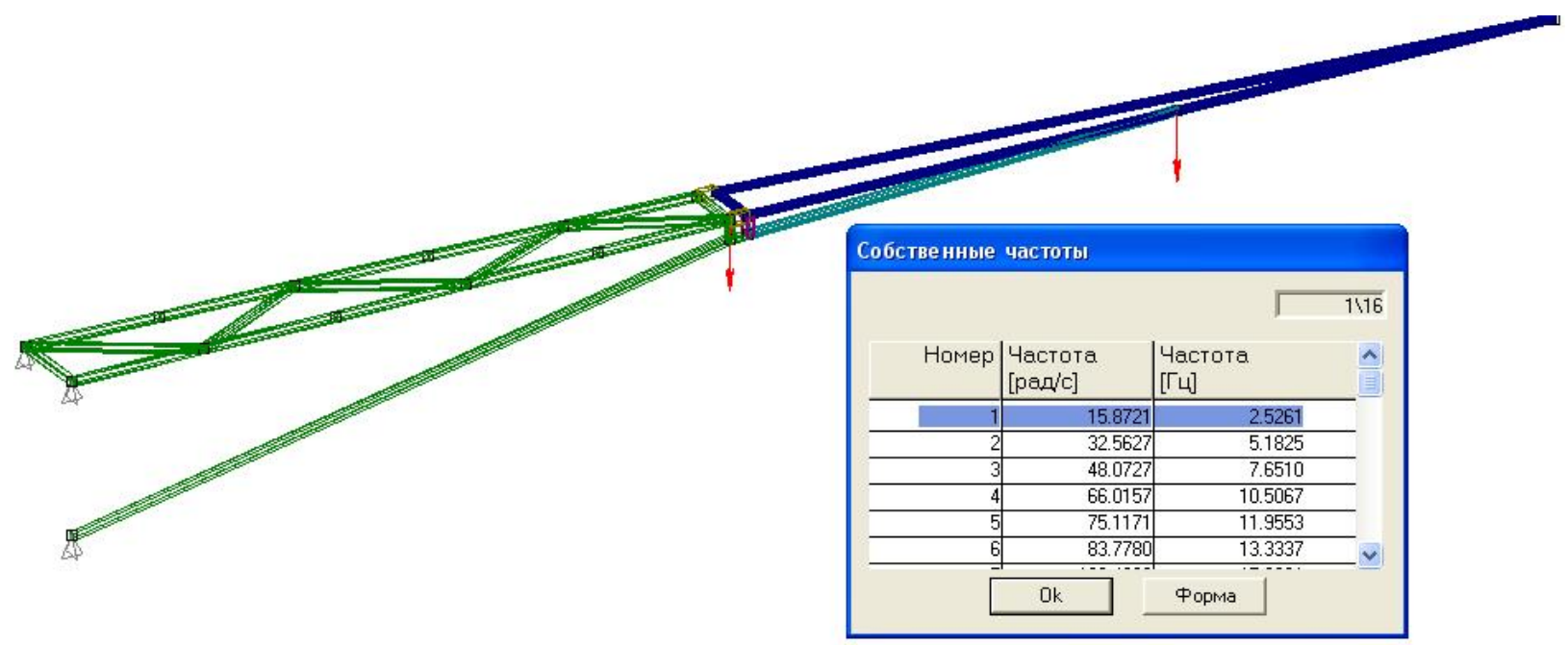

Fig. 35. Frequency characteristics of the rod

The rod of the boom- sprayer is usually flat for a size bar less than $18 \mathrm{~m}$ or spacious constructions for a larger rod. There are bars and box-shaped sections. The sprayer has three load cycles: 1) the transport position; 2) deployment; 3 ) working position. We will consider the working position of the rod. The rod, as well as the overwhelming number of machine elements, should be considered in cyclic loads. The main 
source of dynamic perturbations of the rod sprayer, as well as for each wheeled unit, is the interaction of the wheels with the relief of the field. The character of the wave oscillation and its amplitude-frequency characteristics are shown in Figs. 36, 37 ([76]).

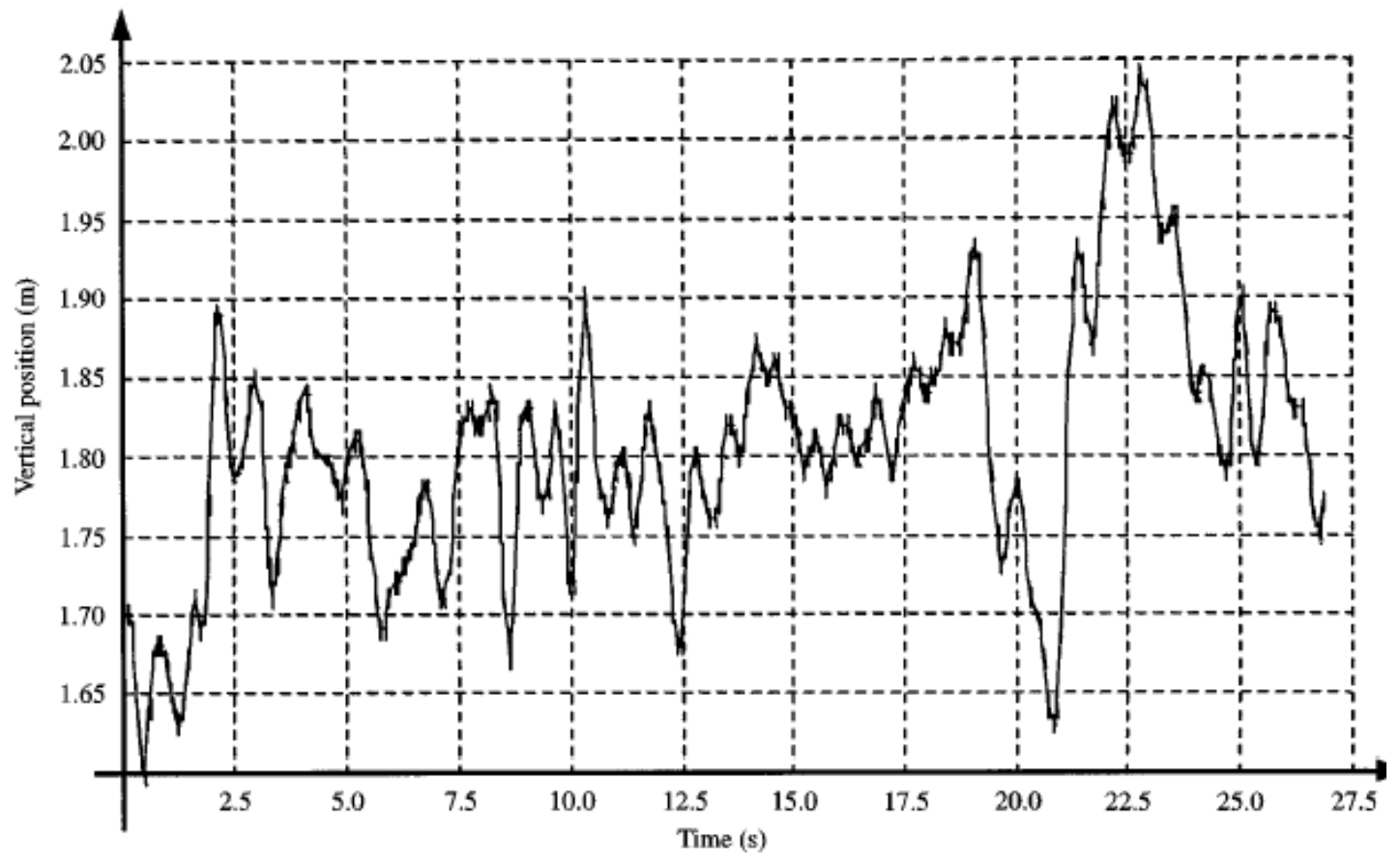

Fig. 36. The character of the wave oscillation of the boom-sprayer

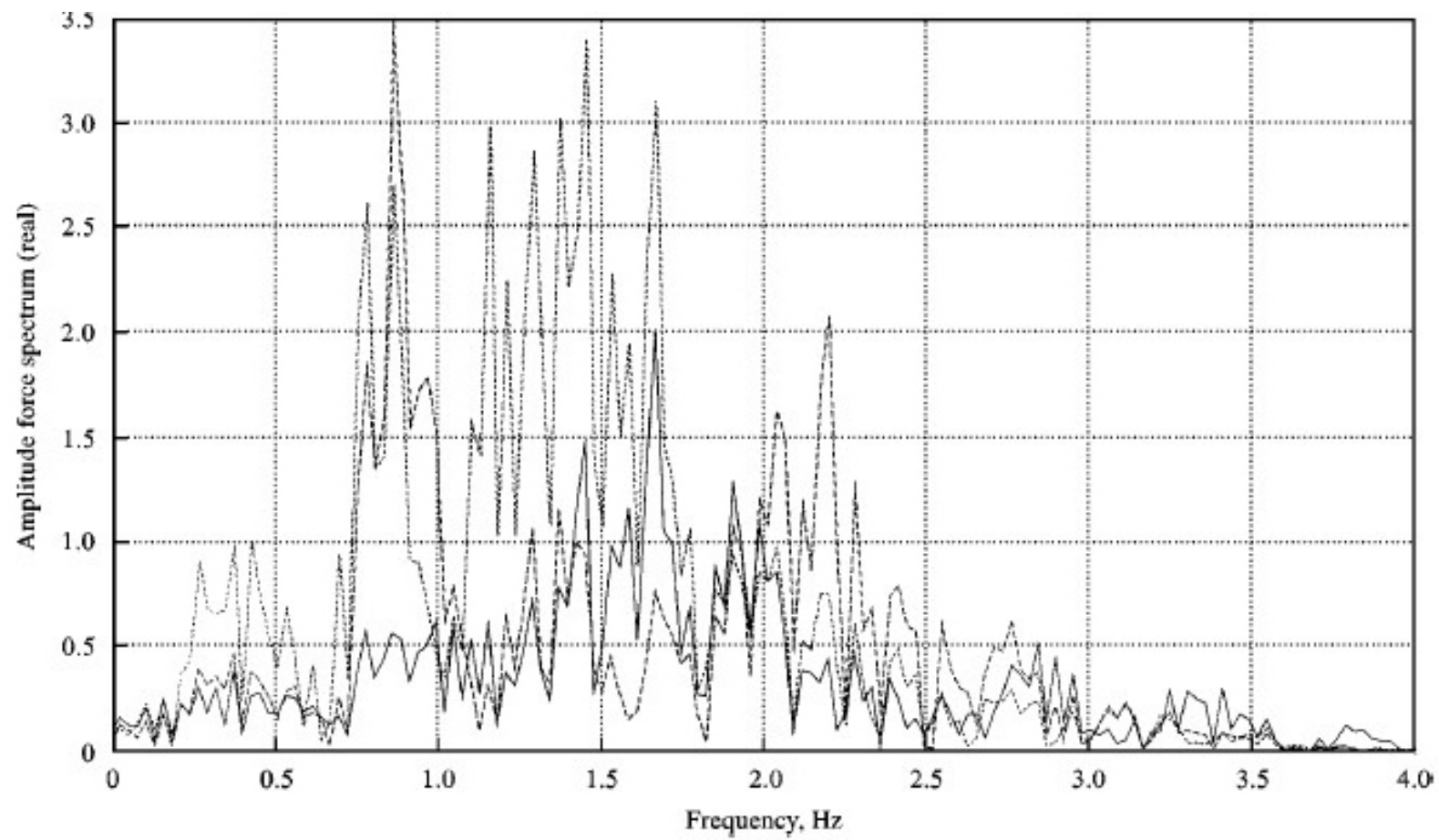

Input force intensities at 4,8 and $12 \mathrm{~km} / \mathrm{h} ;-, 4 \mathrm{~km} / \mathrm{h} ;-\cdots, 8 \mathrm{~km} / \mathrm{h}$;

$12 \mathrm{~km} / \mathrm{h}$

Fig. 37. Frequency characteristics of external perturbation for rod sprayer

They are obtained for various speeds $(4,8,12 \mathrm{~km} / \mathrm{h})$ of the unit on the basis of experimental studies [76]. As can be seen, the frequency characteristics of external perturbations are concentrated in the lowfrequency range. We now define the frequency characteristics of the rod. Fig. 2 shows the wing model of 
an 18-meter rod and its own frequencies obtained using the WinMachin package. The first resonance frequency is $1.8 \mathrm{~Hz}$. Now define the static stiffness at the point indicated by the arrow (Fig. 37). In the $\mathrm{z}$ direction (perpendicular to the farm's plane) we set the force to $1000 \mathrm{n}$ and determine the displacement. Let's give the first form of the vibrations of the farm (Fig. 38) and a stress map at a static load at a point given by an arrow (Fig. 39).

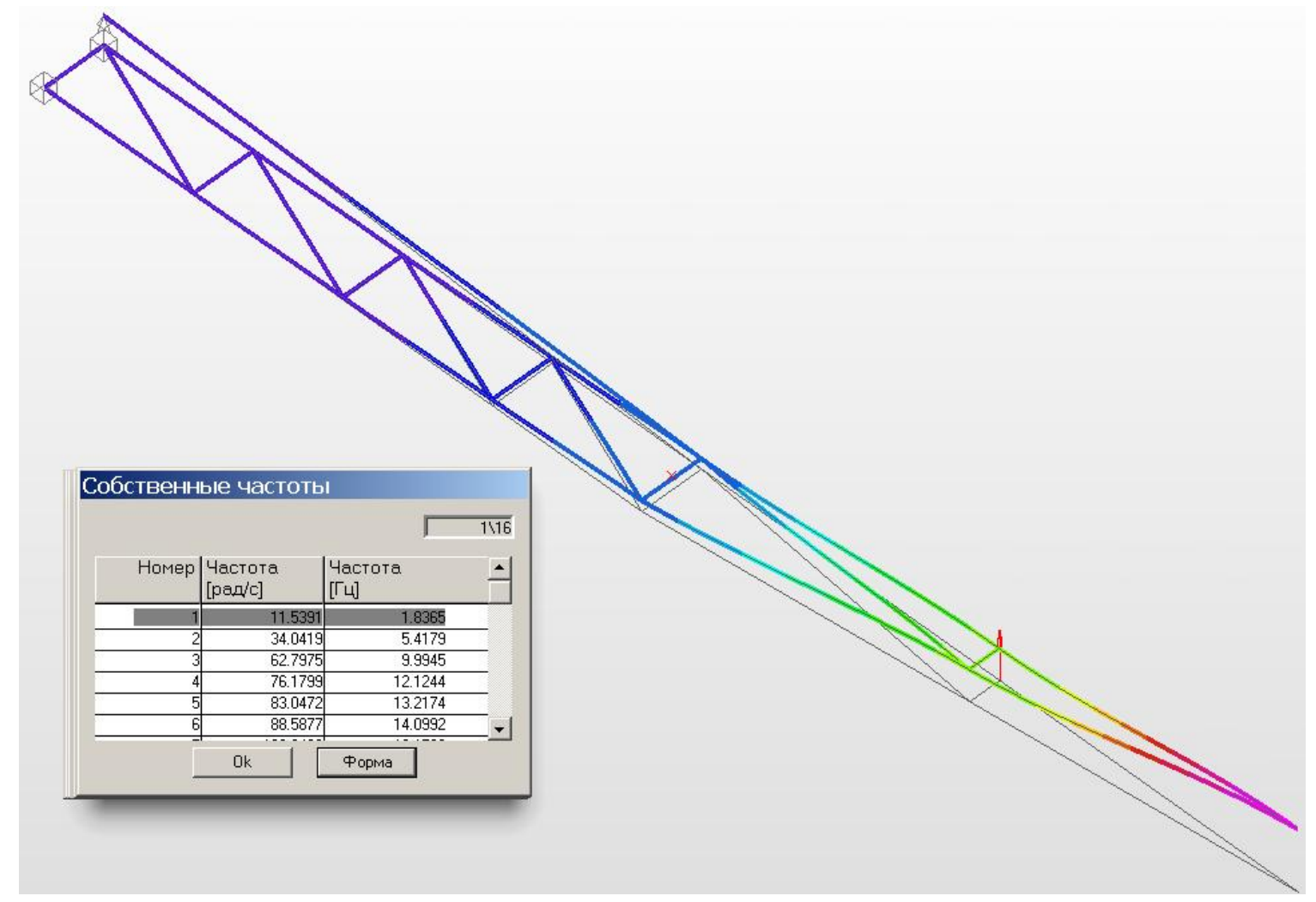

Fig. 38. The first form of boom wing vibration

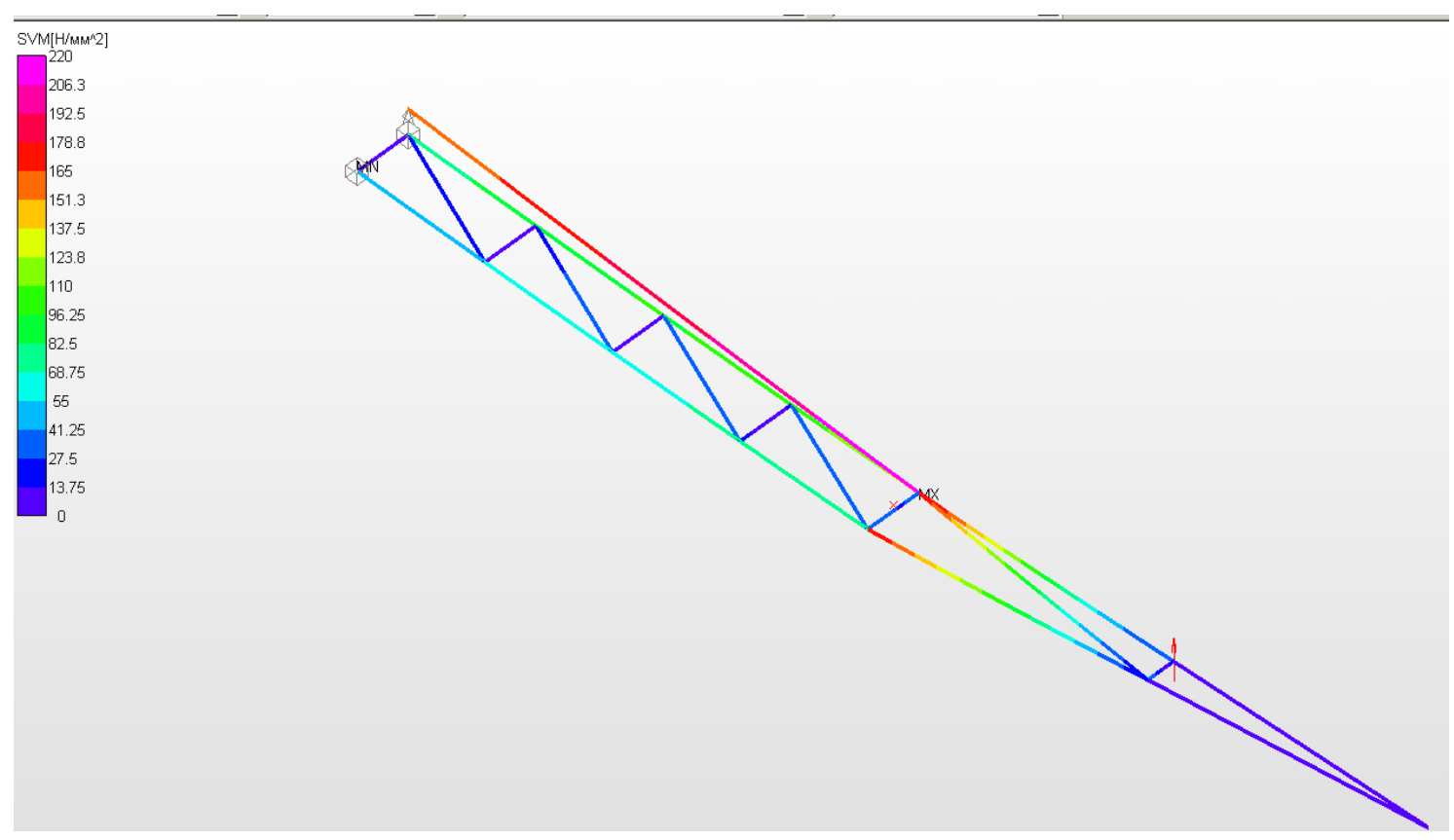

Fig. 39. Stress map at static load 
These data will take us long to construct a mathematical model of the rod wing and determine its parameters.

The basic equation for identification. Given that both the first resonance frequency of the rod wings and the peak of external perturbation are in the low-frequency range, consider the single-mass model of the rod wings (Fig. 40).

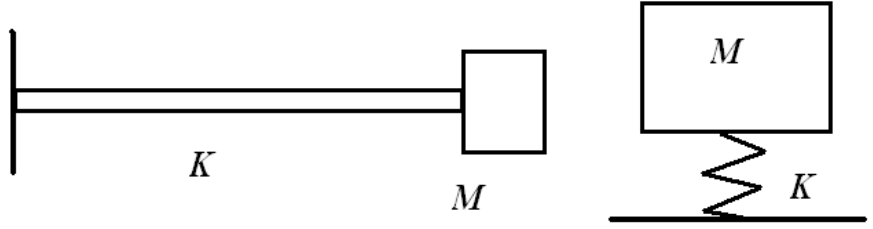

Fig. 40. One-mass model of a rod

This mass is on a weightless rod (Fig. 40), equivalent to the classical one-mass model - the weight on the spring. The calculation model is described by the following differential equation:

$$
m_{1} \frac{d^{2} x_{1}}{d t^{2}}+k_{1} x_{1}+c_{1} \frac{d x_{1}}{d t}=F
$$

where $k_{1}$-appropriate stiffness; $c_{1}$ - coefficient of viscous damping; $x_{1}$ - displacement; $F$ - perturbation. Parameters $m_{1}, k_{1}, c_{1}$ are unknown. Rigidity $k$ is determined on the basis of Fig. 37, 38.

$$
k=F / \Delta \approx 1000 / 0.2195 \approx 4556 \mathrm{~N} / \mathrm{m} .
$$

The mass is now determined on the basis of the formula

$$
m=k / \omega^{2} \approx 4556 / 11.54^{2} \approx 34.2 \mathrm{~kg} \text {. }
$$

The weight in the model is three times smaller than the weight of the rod wing (Fig. 41). Consider the loaded point at the tip of the rod (Fig. 41).

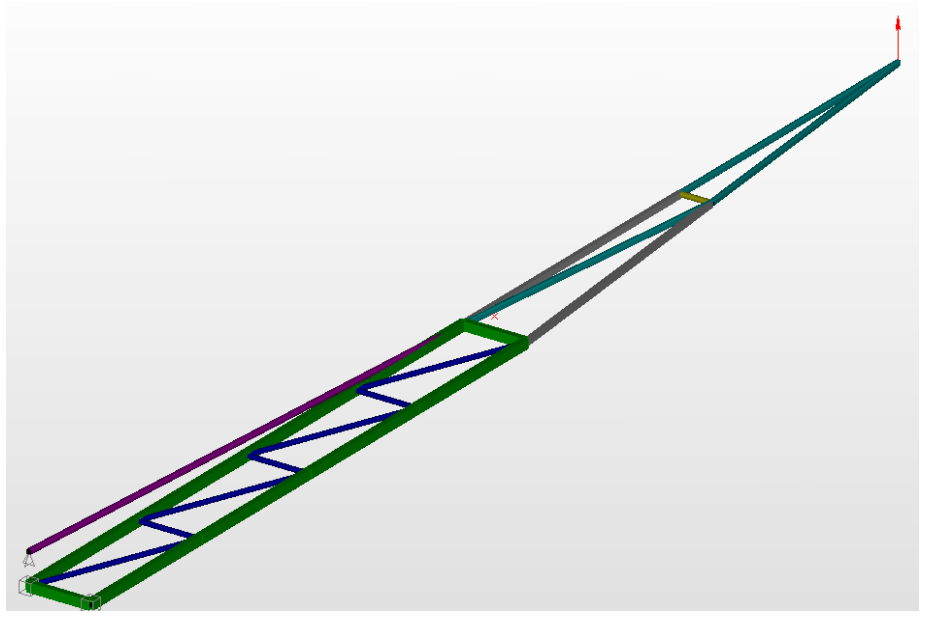

Fig. 41. Loaded point at the tip of the rod

For this case, the rigidity $\mathrm{k}$ is determined on the basis of Fig. 41 and formula (20)

$$
k=F / \Delta \approx 1000 / 0.898 \approx 1136 \mathrm{~N} / \mathrm{m} \text {. }
$$

We now determine the equivalent mass on the basis of formula (21)

$$
m=k / \omega^{2} \approx 1136 / 11.54^{2} \approx 8.5 \mathrm{~kg} \text {. }
$$

It can be seen that the equivalent mass of the wing rod is much smaller than its actual weight, and in the case of calculations at the extreme point (4.5), the equivalent mass is less than an order of magnitude.

\section{Condensed Model of the Beam - DVA}

A dynamic vibration dampers comprising a vibration absorbing inertial element, made in the form of a curvilinear surface and a moving mass, is characterized in that the curvilinear surface is made in the form 
of a plate with an adjustable curvature, and the entire structure is placed in a container with partially filled viscous fluid, which allows, with taking into account the possibility of changing the shape of the plate, the level of liquid in the container, to carry out the precision adjustment of the regulated dynamic flaps to the given operating frequency with simultaneous provision the optimal damping properties.

Let us consider condensed model of impact masses DVA - primary system. In Fig. 41 the impact mass type DVA is presented: an additional impact mass in container with elastic barrier elements. Consider now the DVA with 3 different impact masses in one container (Fig. 42).

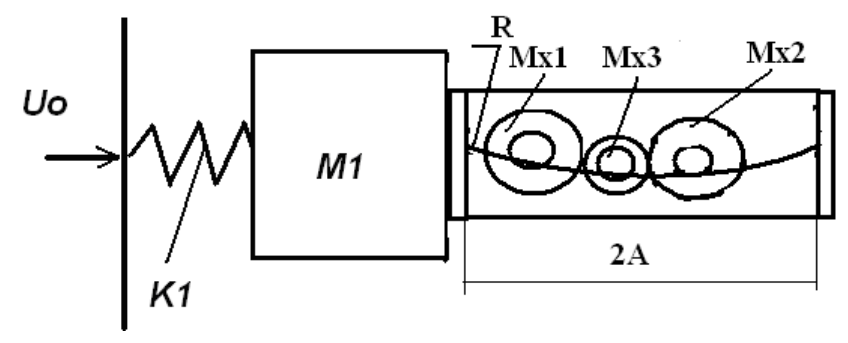

Fig. 42. DVA with 3 different impact masses

The system of equations is now

$$
\begin{gathered}
m_{1} \frac{d^{2} u_{1}}{d t^{2}}+k_{1}\left(u_{1}-u_{0}\right)+k_{A}\left(u_{1}-u_{A}\right)-m_{X 1} / R_{X 1}\left(u_{X 1}-u_{A}\right)+k_{X 1} F_{1}\left(u_{1}-u_{X 1}\right) \\
-\ldots-m_{X N} / R_{X N}\left(u_{X N}-u_{A}\right)+k_{X N} F_{N}\left(u_{1}-u_{X N}\right)=F(t), \\
m_{X 1} \frac{d^{2} u_{X 1}}{d t^{2}}+m_{X 1} / R_{X 1}\left(u_{X 1}-u_{A}\right)-k_{X 1} F_{1}\left(u_{1}-u_{X 1}\right)+F_{12}\left(u_{X 1}, u_{X 2}\right)+F_{13}\left(u_{X 1}, u_{X 3}\right)=0, \\
m_{X 2} \frac{d^{2} u_{X 2}}{d t^{2}}+m_{X 2} / R_{X}\left(u_{X N}-u_{A}\right)-k_{X} F_{N}\left(u_{1}-u_{X 2}\right)-F_{12}\left(u_{X 1}, u_{X 2}\right)+F_{23}\left(u_{X 2}, u_{X 3}\right)=0, \\
m_{X 3} \frac{d^{2} u_{X 3}}{d t^{2}}+m_{X 2} / R_{X}\left(u_{X N}-u_{A}\right)-F_{13}\left(u_{X 1}, u_{X 3}\right)-F_{23}\left(u_{X 2}, u_{X 3}\right)=0 .
\end{gathered}
$$

Here three DVA's masses are considered. Parameters $m_{1}, k_{1}$ of the prime system may be found by means of FEM or experimentally. The nonlinear functions are

$$
F_{i}=-K_{v i}\left(x_{i}-A_{i}\right) \quad\left|x_{x}\right|>A_{i}, \quad F_{i}=0 \quad\left|x_{i}\right|<A_{i} \quad ; F(t)=a \sin (\omega t),
$$

where $A$ - clearance and $K_{v i}$ - boundary elements rigidity. The nonlinear functions $F_{13}\left(u_{X 1}, u_{X 3}\right)$, $F_{23}\left(u_{X 2}, u_{X 3}\right)$ of DVA's masses interaction may be defined analogously.

$$
\begin{array}{cccc}
F_{13}=F_{13}\left(x_{1}-x_{3}\right) & \left|x_{1}-x_{3}\right|<R_{1}+R_{3}, & F_{13}=0 & \left|x_{1}-x_{3}\right|>R_{1}+R_{3}, \\
F_{23}=F_{13}\left(x_{2}-x_{3}\right) & \left|x_{2}-x_{3}\right|<R_{2}+R_{3}, & F_{23}=0 & \left|x_{2}-x_{3}\right|>R_{2}+R_{3} .
\end{array}
$$

Let us consider the optimization of this DVA's by criterion

$$
C i L=\operatorname{Max}\left(x_{1}(t)\right), t>t_{P} .
$$

Coordinates $x_{1}, x_{2}, x_{3}$ of the impact masses and the differences between this coordinates $x_{1}, x_{3}$ and $x_{2}, x_{3}$ are presented in Fig. 43. In Fig. 44 the results of DVA's application are shown.

The 3 mass impacts DVA seems to be better then independent 3 DVA's with the same masses. Here the optimization in the real time is done. Present research develops the genetic algorithms for optimal design searching by discrete-continuum DVA's system - base system modeling [77-80]. The process of geometrical DVA's parameters evolution for different stage of impulse loading and different base system damping is shown in Fig. 45. 


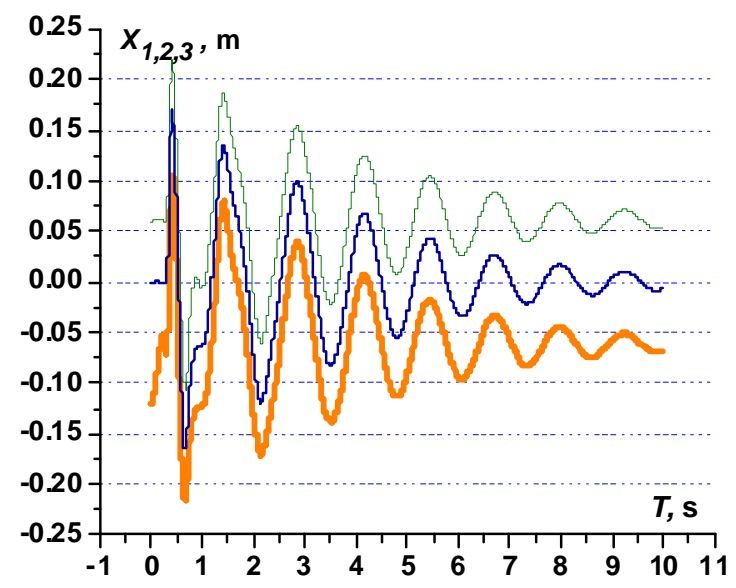

$a$

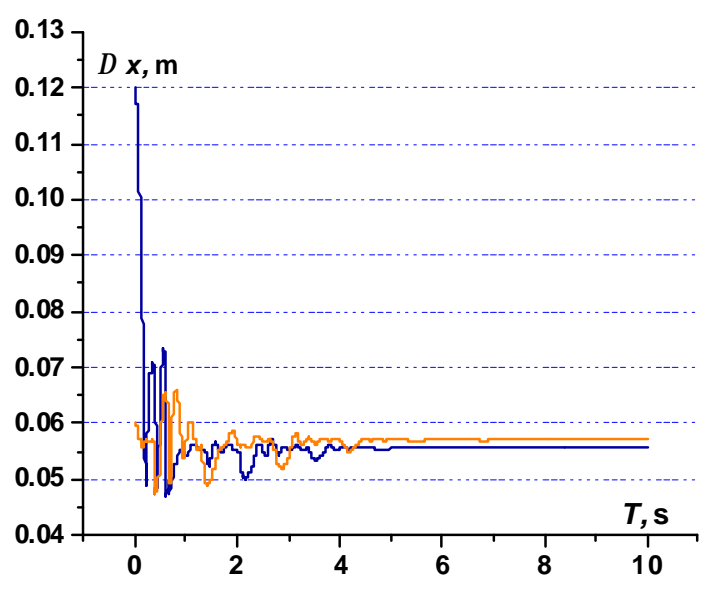

$b$

Fig. 43. Coordinates $x_{1}, x_{2}, x_{3}$ of the impact masses (a); the differences between this coordinates $x_{1}, x_{3}$ and $x_{2}, x_{3}(b)$

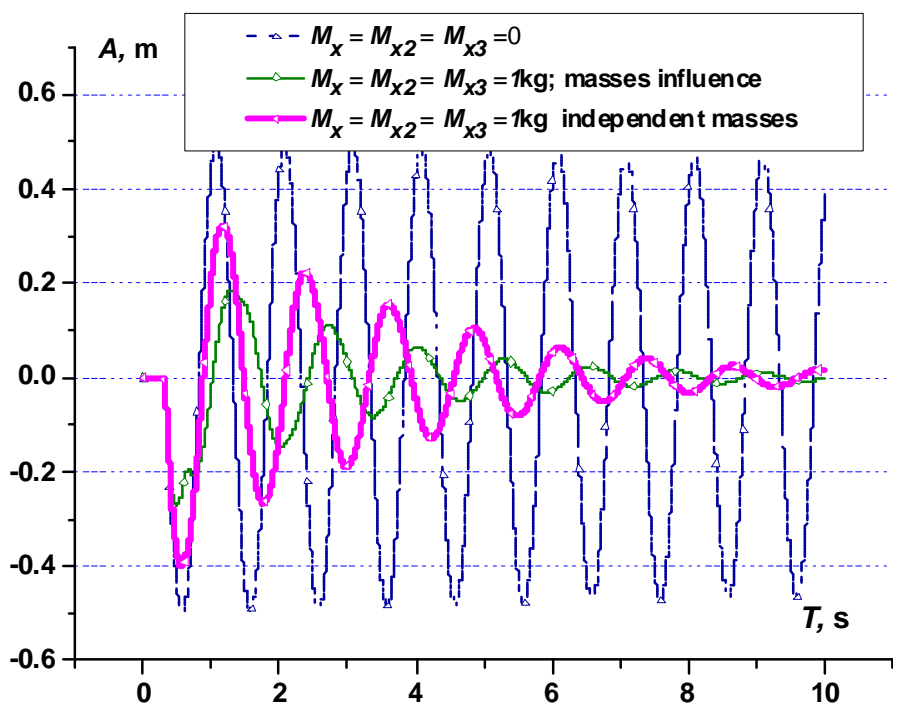

Fig. 44. Results of DVA's application $\mathrm{N}=1$

Dx .317E-01 DG .192E-01 Mx3 .279E+01 Mx .107E+00 CiL .242E-01 fx .532E+00 fKK .983E+00 fEkx .101E+01 Ax .218E+02 $\mathrm{N}=2874$

Dx .432E-01 DG .433E-01 Mx3 .282E+01 Mx .923E-01 CiL .161E-01 fx .456E+00 fKK .105E+01 fEkx .101E+01 Ax .140E+02 $\mathrm{N}=3892$

Dx .426E-01 DG .434E-01 Mx3 .282E+01 Mx .911E-01 CiL .161E-01 fx .455E+00 fKK .105E+01 fEkx .101E+01 Ax .140E+02

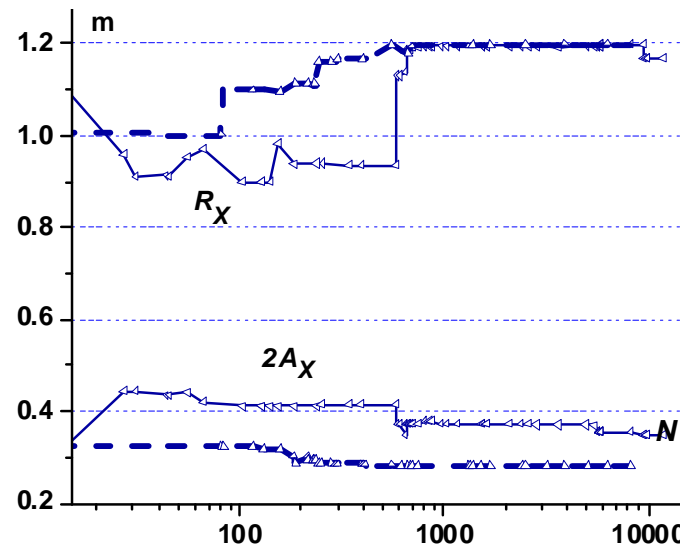

Fig. 45. Process of geometrical DVA's parameters evolution for different stage of impulse loading

Here 8 parameters of optimization are used: fx, fx2 DVA's eigenfrequencies; Dx, DG - proportional viscous damping in container and in barrier (added to all equations terms $k_{X i} D_{X i} d u_{i} / d t$ ), $M x 3-$ less DVA' 
mass, fKK - DVA's masses inter-collision and fKx - DVA's masses on barrier collision eigenfrequencies. Ax is clearance half length. The prime system mass is $m_{1}=10 \mathrm{~kg}$, the prime system eigenfrequency $f_{R}=1 \mathrm{~Hz}=6.28 \mathrm{Rad} / \mathrm{s}$, the proportional damping $-D 1=0.03$.

In Fig. 46 results of one-mass DVA and 3 mass DVA optimization are shown.

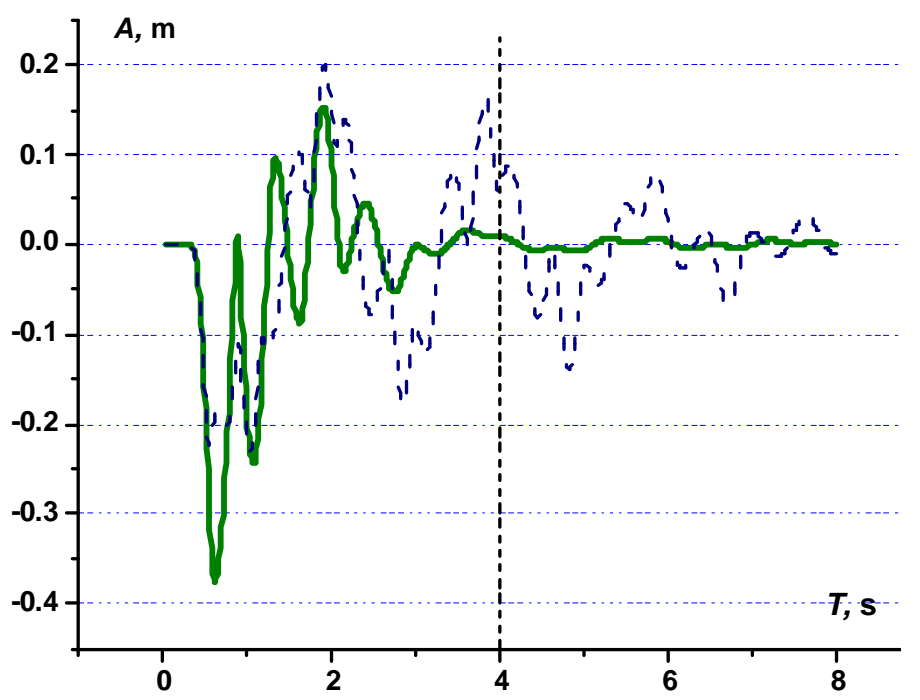

Fig. 46. Results of one-mass DVA (dash line) and 3 mass DVA optimization

The one-mass DVA is worse than 3-mass. The upper results are achieved with the Boltzman approximation for contact forces [80]. In Fig. 47 the experimental example of this DVA (in natural size) is shown.
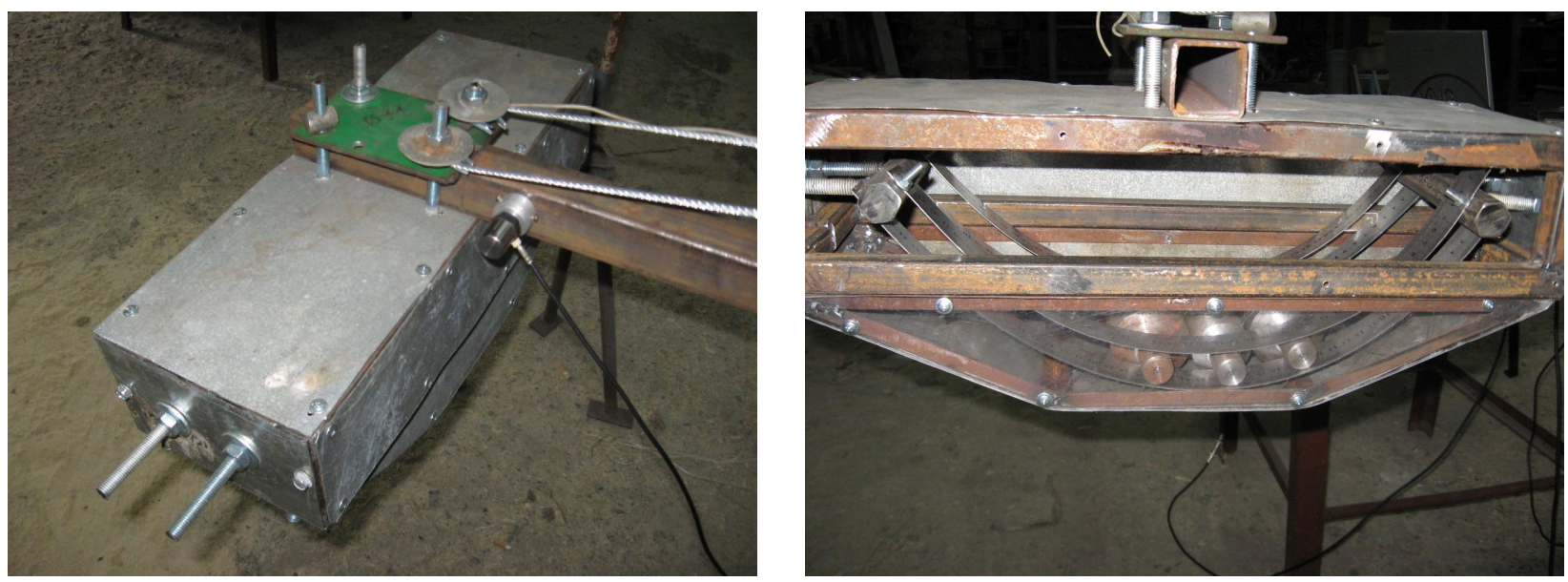

Fig. 47. The experimental example of DVA (in natural size)

Experimental results are the same as in Fig. 45. This was achieved by the DVA frequency regulation [74] and high damping as result of dry friction in the masses contacts.

(B) Elastic-pendulum DVA. Consider the elastic-pendulum DVA, which is often used in high-rise buildings (see Fig. 7). The scheme of this DVA is shown in Fig. 48.

The equation of the dynamics of such a DVA will be

$$
\begin{gathered}
m_{1} \frac{d^{2} u_{1}}{d t^{2}}+k_{1}\left(u_{1}-u_{0}\right)+k_{A}\left(u_{1}-u_{A}\right)+m_{A} L\left(u_{1}-u_{A}\right)=0, \\
m_{A} \frac{d^{2} u_{A}}{d t^{2}}+k_{A}\left(u_{A}-u_{0}\right)-m_{A} L\left(u_{1}-u_{A}\right)=0 .
\end{gathered}
$$


The only difference from the usual one-mass DVA is that instead of one coefficient of rigidity we have a combined: elastic-pendulum coefficient.

$$
k_{A}+1 / L
$$

However, in real DVA designs, the additional bond mainly includes not only elastic elements, but also damping elements, as well as nonlinear elements of dry friction and barrier functions. As in the case of a jack-type jacket with barriers, the nonlinear dynamics equations will be

$$
\begin{gathered}
m_{1} \frac{d^{2} u_{1}}{d t^{2}}+k_{1}\left(\left(u_{1}-u_{0}\right)+\eta_{1}\left(\frac{d u_{1}}{d t}-\frac{d u_{0}}{d t}\right)\right)+m_{A} L\left(\left(u_{1}-u_{A}\right)+\eta_{A m}\left(\frac{d u_{1}}{d t}-\frac{d u_{A}}{d t}\right)\right)+F_{n}=0, \\
m_{A} \frac{d^{2} u_{A}}{d t^{2}}-m_{A} L\left(\left(u_{1}-u_{A}\right)+\eta_{A m}\left(\frac{d u_{1}}{d t}-\frac{d u_{A}}{d t}\right)\right)-k_{A}\left(\left(u_{1}-u_{A}\right)+\eta_{A}\left(\frac{d u_{1}}{d t}-\frac{d u_{A}}{d t}\right)\right)-F_{n}=0 .
\end{gathered}
$$

Parameters $m_{1}, k_{1}, m_{A}, k_{A}$ are indicated in Fig. 48. Nonlinear functions characterizing the interaction of the mass of DVA with elastic barriers and dry friction will be

$$
F_{n}=F_{B}+F_{T} \text {, where }
$$

$$
\begin{gathered}
F_{B}=k_{B}\left(\left(x_{A}-x_{1}-A_{i}\right)+\eta_{B}\left(\frac{d u_{A}}{d t}-\frac{d u_{1}}{d t}\right)\right), \quad\left|x_{A}-x_{1}\right|>A_{i}, \quad F_{B}=0 \quad\left|x_{A}-x_{0}\right|<A_{i}, \\
F_{T}=k_{T} \operatorname{sign}\left(\frac{d u_{A}}{d t}-\frac{d u_{1}}{d t}\right) .
\end{gathered}
$$

Here it was still possible to take into account dry friction in the hinges of the pendulum suspension, but it, as well as damping in this suspension is rather small (especially when the mass of DVA is suspended on ropes) and is not taken into account. As before, for this system of equations (1), a counting program for Fortran was compiled. The results for some practical applications are given below. Below (Fig. 49) the FRF's are optimized for DVA for different masses of the basis and frequency range.

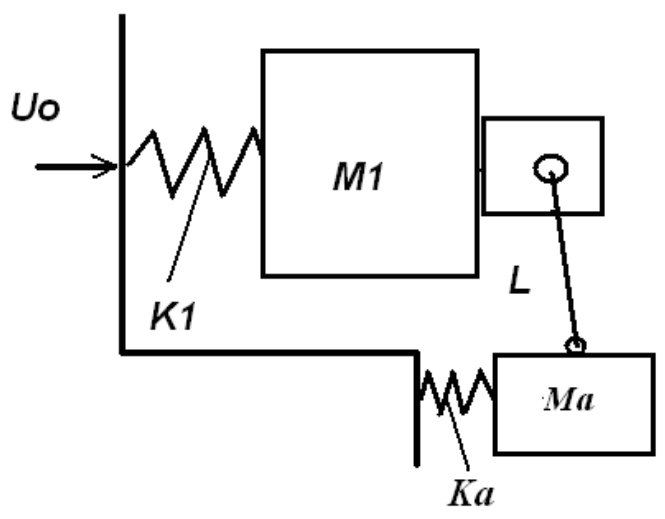

Fig. 48. Elastic-pendular DVA

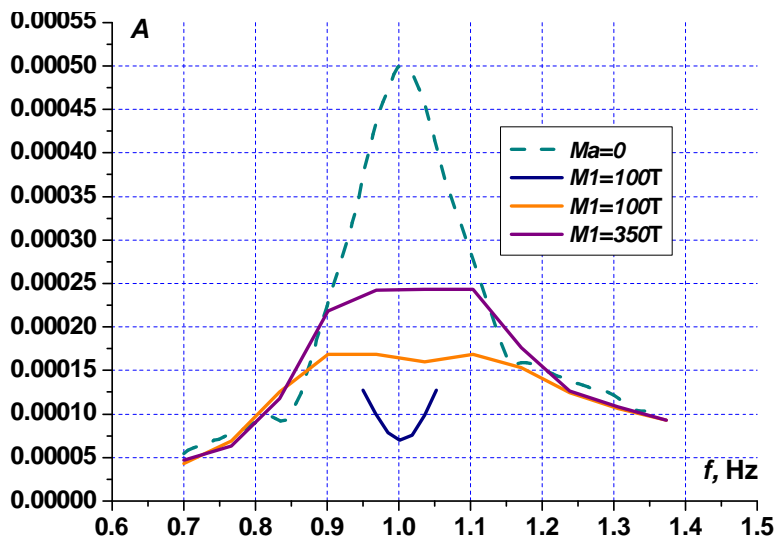

Fig. 49. FRF's optimized for DVA for different masses of the base and frequency range

The frequency response is much higher than in [31]. That is, graphs in [31] are unrealistic.

\section{The Equation for Basic Building Identification}

Given that both the first resonance frequency of pre-heater tower and the peak of external perturbation are in the low-frequency range, consider the single-mass model of the tower as above for the rod wings (Fig. 39). Now, rigidity $\mathrm{k}$ is determined on the basis of Fig. 50.

$$
k=F / \Delta \approx 10000 / 0.00095 \approx 10 \cdot 10^{6} \mathrm{~N} / \mathrm{m} .
$$

The mass is now determined on the basis of the formula

$$
m=k / \omega^{2} \approx 10 \cdot 10^{6} / 36^{2} \approx 280000 \mathrm{~kg} \text {. }
$$


The weight in the model is 5 times smaller than the weight $1400000 \mathrm{~kg}$ of the tower (Fig. 7).

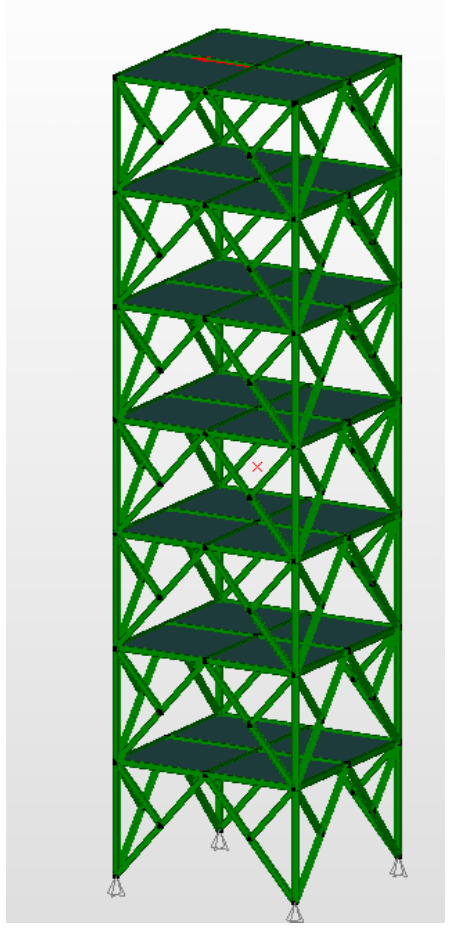

$a$
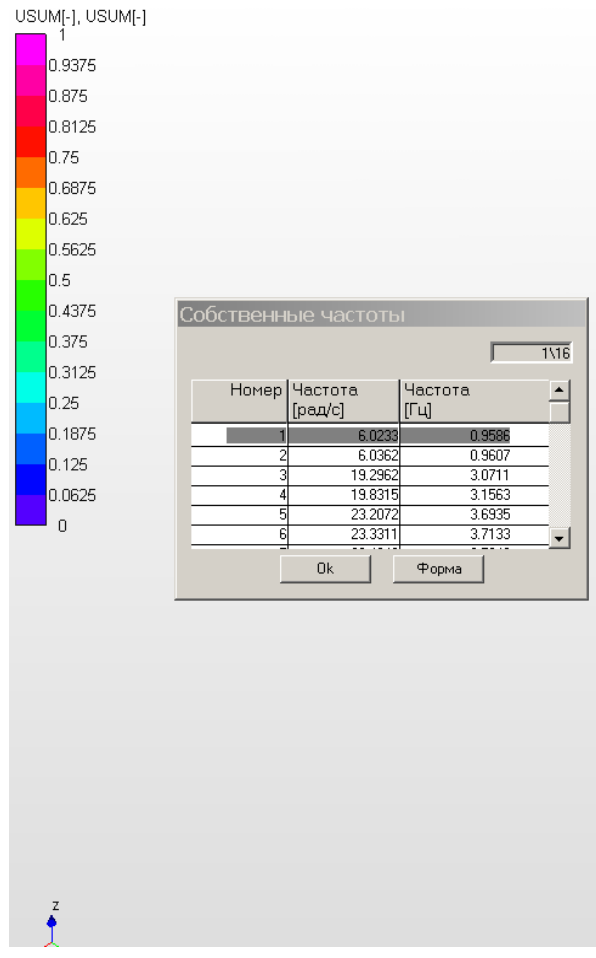

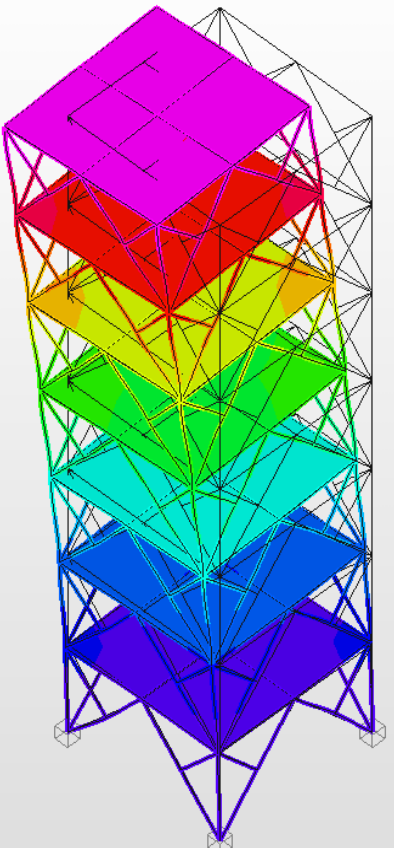

$b$

Fig. 50. The tower design (a); results of modeling by FE (b)

Let's consider the frequency response of uncontrolled and controlled by the damping of DVA for the tower (Fig. 51). The use of controlled DVA improves the result by 2 times. The vibration response in uncontrolled and controlled by the damping of DVA is presented in Fig. 52.

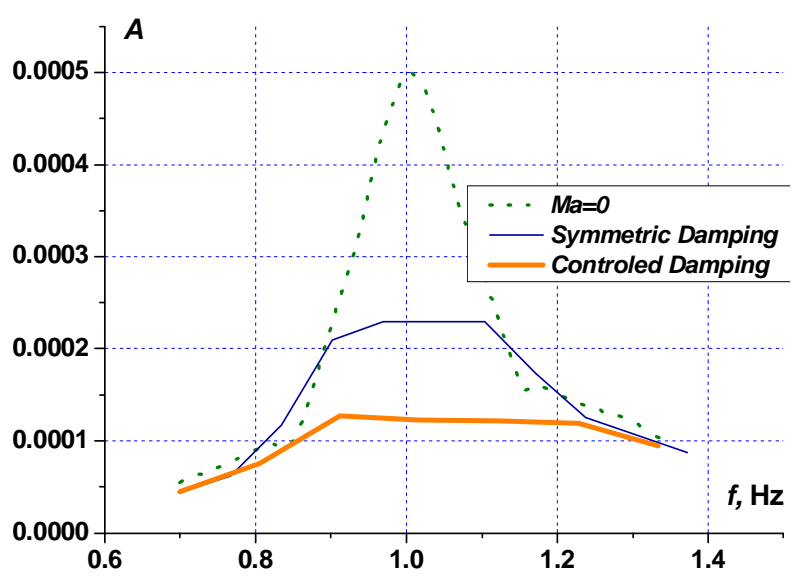

Fig. 51. The frequency response is uncontrolled and controlled by the damping of DVA

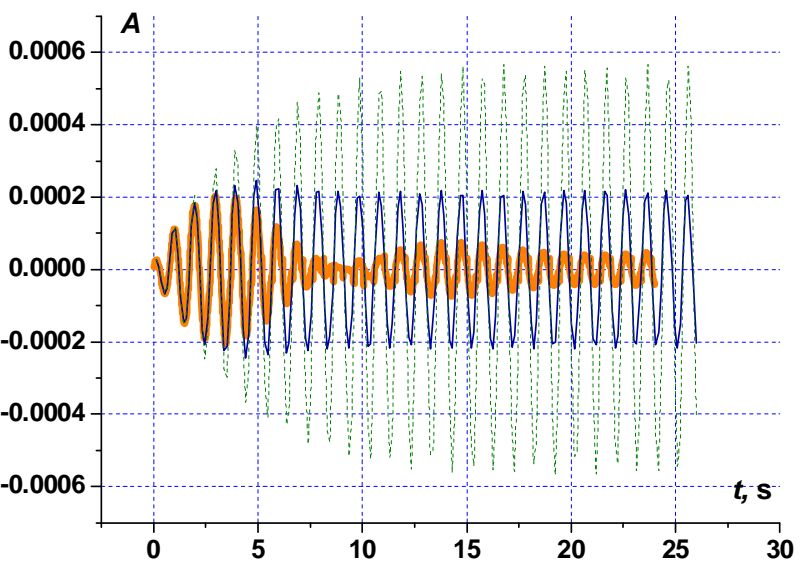

Fig. 52. The vibration response in uncontrolled and controlled by the damping of DVA

The practical design of DVA for high-rise buildings ([73]). The basis of the useful model is the task of ensuring smooth control of the frequency and damping characteristics of DVA and the implementation of effective vibration absorption in a wide frequency range on two axes. The given task is achieved by the fact that in a dynamic oscillation chamber containing a vibration absorbing inertial element, made in the form of a mobile box filled with granular material and limited by elastic barriers, on guides of curvilinear surfaces, several special radius balls are used, the curvilinear surface is made in the 
form plates of spherical shape with a given curvature and the whole structure can move in its plane, which allows, taking into account the possibility of changing the stiffness of elastic fastening By changing the stiffness by changing the curvature of one of the plates using the electromechanical automatic control circuit, adjusting the clamping devices, making a precise adjustment of the adjustable dynamic flap on two axes in the wide-band range.

Fig. 53 schematically depicts a DVA (top view) with a moving body 1 in the form of a box that rests on three ball bearings 3 and is limited by elastic barriers 8 in the form of curvilinear plates, one plate 9 changes its curvature under the action of the clamping device 7.

Fig. 54 schematically depicted DVA (side view) based on three ball bearings, each of which consists of a ball 5 rotating on a spherical surface of the plate 6 and moving along the surface of the damaged object 2 and controlled by the clamping device 7 and granulated material 4 in the box.

To adjust the main vibration absorber, a plate of variable radius, together with an automatic control circuit, is used. The ice is used as a driving force for pusher movement. When you move the plate with the help of LED, the distance radius of the plate increases, and thus the frequency of DVA increases.

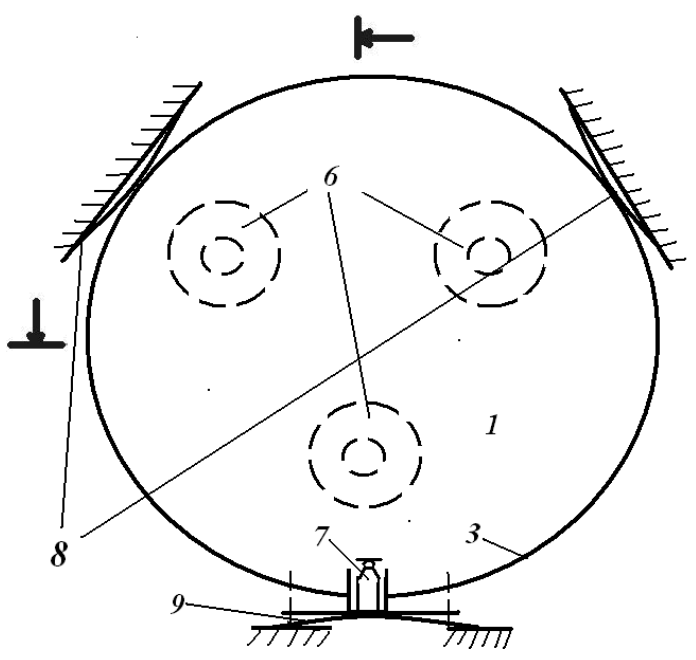

Fig. 53. Schematic of DVA (top view)

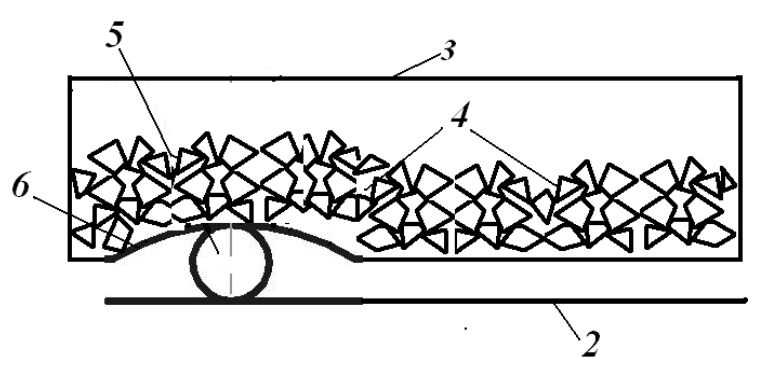

Fig. 54. Schematic of DVA (side view)

\section{Conclusions}

In this paper, we consider a number of issues of optimal design of dynamic oscillation absorbers. Below is a historical essay on the emergence of the theory of DVA and an overview of the latest results. The semiactive DVAs, which are controlled both by damping and frequency, are considered. As a practical application, fluctuations of the rods of a rod sprayer in a horizontal plane with attached DVA are considered. Also, the use of DVA for the tower is considered. To determine the dynamic characteristics of these structures, the FEM was used. On its basis, condensed models of these basic structures are obtained, mainly in the form of SDOF. On the basis of these simple models, it is possible to optimize different types of DVA in the range of the first resonance of the basis, where, as a rule, the greatest amplitudes of oscillations. Separately, various types of DVA control: skyhook (different types), ON-OFF, Bang-Bang are investigated. It has been found that ON-OFF control is only effective with the measurements of the relative speed of the DVA and the displacement of the basic design. Some DVA constructions are presented: the impact mass type DVA with an additional impact mass in container with elastic barrier elements; two-axes DVA with a moving body in the form of a box that rests on three ball bearings and is limited by elastic barriers in the form of curvilinear plates, one plate changes its curvature under the action of the clamping device for the DVA frequency regulation.

\section{References}

[1] M. Constantinou, T. Soong, and G. Dargush, "Passive Energy Dissipation Systems for Structural Design and Retrofit", Multidisciplinary Center for Earthquake Engineering Research, 1998. 
[2] C. Truesdell, A First Course in Rational Continuum Mechanics. New York: Academic Press, 1977.

[3] H. Ashley, "On passive damping mechanisms in large space structures", Journal of Spacecraft and Rockets, vol. 21, no. 5, pp. 448-455, 1984.

[4] G. S. Pisarenko, A. P. Yakovlev, and V. V. Matveev, Vibropogloshchaiushchie svoistva konstruktcionnykh materialov [Vibration absorption properties of structural materials]. Kyiv, Ukraine: Naukova Dumka Publ., 1971. [in Russian].

[5] V. G. Karnaukhov, and I. F. Kirichok, Sviazannye zadachi teorii viazko-uprugikh plastin i obolochek [Related problems of the theory of visco-elastic plates and shells]. Kyiv, Ukraine: Naukova Dumka Publ., 1986. [in Russian].

[6] E. E. Ungar, and E. M. Kerwin, "Loss factors of viscoelastic systems in terms of energy concepts", The Journal of the Acoustical Society of America, vol. 34, no. 7, pp. 954-957, 1962.

[7] S. H. Crandall, "The role of damping in vibration theory", Journal of Sound and Vibration, vol. 11, no. 1, pp. 3-18, 1970 .

[8] S. H. Crandall, "The hysteretic damping model in vibration theory", Journal of Mechanical Engineering Science, no. 205, pp. 23-28, 1991.

[9] R. H. Scanlan, "Linear damping models and causality in vibrations", Journal of Sound and Vibration, vol. 13, no. 4, pp. 499-503, 1970.

[10] D. E. Newland, Mechanical Vibration Analysis and Computation. New York: Longman, Harlow and John Wiley, 1989.

[11] O. C. Zienkiewicz, and R. L. Taylor, The Finite Element Method. London, UK: McGraw-Hill, 1989.

[12] F. Brezzi, and M. Fortin, Mixed and Hybrid Finite Element Methods. New York: Springer-Verlag, 1991.

[13] K. J. Bathe, Finite Element Procedures. Watertown, MA: Prentice Hall, Pearson Education, Inc., 1996.

[14] C. L. Dym, and I. H. Shames, Energy and Finite Element Methods in Structural Mechanics. New York: Hemisphere, 1985.

[15] J. N. Reddy, An Introduction to the Finite Element Method. New York: McGraw-Hill, 2006.

[16] S. Snowdon, Vibration and Shock in Damped Mechanical Systems. New York: Wiley, 1968.

[17] D. Braess, Finite Elements: Theory, Fast Solvers, and Applications in Solid Mechanics. Cambridge, UK: Cambridge University Press, 2007.

[18] J. P. Boyd, Chebyshev and Fourier Spectral Methods. New York: Dover Publications, 2001.

[19] G. S. Payette, "Spectral/hp finite element models for fluids and structures", ProQuest Dissertations and Theses, SAND2012-7615, 2012.

[20] Kazuto Seto, "Active vibration control in machinery", Journal of the Acoustical Society of Japan, vol. 12, issue 6, pp. 263-272, 1991.

[21] M. J. Balas, "Feedback Control of Flexible Systems", IEEE Trans. Automat. Contr., pp. 673-679, 1978.

[22] C. Moutinho, "Testing a simple control law to reduce broadband frequency harmonic vibrations using semi-active tuned mass dampers", Smart Mater. Struct., vol. 24, 055007, 2005.

[23] D. J. Mead, Passive vibration control. Chichester: John Wiley \& Sons, 2000.

[24] A. D. Nashif, D. I. G. Jones, and J. P. Henderson, Passive vibration control. New York: John Wiley and Sons, 1985 .

[25] J. B. Hunt, Dynamic Vibration Absorbers. London, UK: Mechanical Engineering Publications, 1979.

[26] J. Sun, M. Jolly and M. Norris, “Adaptive and Active Tuned Vibration Absorbers - A Survey”, Journal of Vibration and Acoustics, vol. 117 (B), pp. 234-242, 1995.

[27] N. Carpineto, W. Lacarbonara, and F. Vestroni, "Mitigation of Pedestrian-induced Vibrations in Suspension Footbridges via Multiple Tuned Mass Dampers", Journal of Vibration and Control, vol. 16, no. 5, pp. 749-776, 2010.

[28] I. Kourakis, "Structural systems and tuned mass dampers of super-tall buildings: case study of Taipei 101", Thesis (M. Eng.), Dept. of Civil and Environmental Engineering, Massachusetts Institute of Technology, Cambridge, MA, 2007.

[29] D. E. Newland, "Vibration of the London Millennium Bridge: cause and cure", International Journal of Acoustics and Vibrations, vol. 8, no. 1, pp. 9-14, 2003.

[30] P. Nawrotzki, "Tuned-mass systems for the dynamic upgrade," in Proceedings of Eleventh East AsiaPacific Conference on Structural Engineering and Construction (EASEC-11), Taiwan, 2008, pp. 1-9.

[31] K. Y. Sanliturk, and H. T. Belek, "Tuned-mass systems for the dynamic upgrade", in Proceedings of the 8th International Congress on Sound and Vibration, Hong Kong, 2001, pp. 2259-2264. 
[32] H. Frahm, "Device for damping vibration of bodies", U.S. Patent 989958, Apr. 18, 1911.

[33] P.Watts, "On a method of reducing the rolling of ships at sea", The Royal Institution of Naval Architects, vol. 24, pp. 165-190, 1883.

[34] J. B. Hunt, and J. C. Hissen, "The broadband dynamic vibration absorber", Journal of Sound and Vibration, vol. 83, no. 4, pp. 573-578, 1982.

[35] J. Ormondroyd, J. P. den Hartog, "The theory of the dynamic vibration absorber", Transactions of the American Society of Mechanical Engineers, vol. 50, A9-A22, 1928.

[36] J. P. den Hartog, Mechanical Vibrations. New York: Dover Publications, 1985.

[37] S. Timoshenko, Vibration problems in engineering. New York: Van Nostrand Company, 1955.

[38] B. G. Korenev, and L. M. Reznikov, Dynamic Vibration Absorbers: Theory and Technical Applications. Chichester, UK: J.Wiley \& Sons, 1993.

[39] J. Sun, M. Jolly and M. Norris, "Adaptive and Active Tuned Vibration Absorbers - A Survey", Journal of Vibration and Acoustics, vol. 117 (B), pp. 234-242, 1995.

[40] R. E. D. Bishop, and D. B. Welbourn, "The problem of the dynamic vibration absorber", Engineering, pp. 174-769, 1952.

[41] G. B. Warburton, "On the theory of the acceleration damper", J. Appl. Mech., vol. 24, pp. 322-324, 1957.

[42] J. C. Snowdon, "Platelike Dynamic Vibration Absorbers", Journal of Engineering for Industry, vol. 97, issue 1, pp. 88-93, 1975.

[43] T. Aida, T. Aso, K. Nakamoto, and K. Kawazoe, "Vibration control of shallow shell structures using shell-type dynamic vibration absorber", Journal of Sound and Vibration, vol. 218, issue 2, pp. 245-267, 1998.

[44] M. Z. Kolovsky, Nonlinear Dynamics of Active and Passive Systems of Vibration Protection. Berlin, Germany: Springer Verlag, 1999.

[45] H. Kauderer, Nichtlineare Mechanik. Berlin, Germany: Springer Verlag, 1958. [in German]. 1953.

[46] L. A. Pipes, "Analysis of a nonlinear dynamic vibration absorber", J. Appl. Mech., vol. 20, pp. 515-518,

[47] R. E. Roberson, "Synthesis of a nonlinear vibration absorber", J. Franklin Inst., vol. 254, pp. 105-120, 1952.

[48] R. A. Ibrahim, "Recent advances in nonlinear passive vibration isolators", Journal of Sound and Vibration, vol. 314, issue 3-5, pp. 371-452, 2008.

[49] J. Park, S. Wang, and M. J. Crocker, "Mass loaded resonance of a single unit impact damper caused by impacts and the resulting kinetic energy influx", Journal of Sound and Vibration, vol. 323, issue 3-5, pp. 495-1090, 2009 .

[50] M. Saeki, "Analytical study of multi-particle damping", Journal of Sound and Vibration, vol. 281, issue 3-5, pp. 1133-1144, 2005.

[51] K. S. Marhadi, and V. K. Kinra, "Particle impact damping: effect of mass ratio, material, and shape", Journal of Sound and Vibration, vol. 283, issue 1-2, pp. 433-448, 2005.

[52] B. M. Shah, et al., "Construction and characterization of a particle-based thrust damping system", Journal of Sound and Vibration, vol. 326, issue 3-5, pp. 489-502, 2009.

[53] B. Diveyev, I. Vikovych, I. Dorosh, and I. Kernytskyy, "Different type vibration absorbers design for beam-like structures", in Proceedings of the 19th International Congress on Sound and Vibration, Vilnius, Lithuania, 2012, pp. 1499-1507.

[54] H. Cherchyk, B. Diveyev, V. Martyn, and R. Sava, "Parameters identification of particle vibration absorber for rotating machines", in Proceedings of the 21st International Congress on Sound and Vibration, Beijing, China, 2014, pp. 5:4233-4240.

[55] B. Diveyev, I. Vikovych, V. Martyn, and I. Dorosh, "Optimization of the impact and particle vibration absorbers", in Proceedings of the 22nd International Congress on Sound and Vibration, Florence, Italy, 2015, Code 121474.

[56] O. S. Lanets, Vysokoefektyvni mizhrezonansni vibratsiini mashyny z elektromahnitnym pryvodom (Teoretychni osnovy ta praktyka stvorennia) [High-performance inter-resonant vibrating machines with electromagnetic drive (Theoretical Foundations and Creation Practices)]. Lviv, Ukraine: Lviv Polytechnic Publishing House, 2008. [in Ukrainian].

[57] F. Casciati, G. Magonette, and F. Marazzi, Technology of Semiactive Devices and Applications in Vibration Mitigation. New York: Wiley, 2006. 
[58] F. Weber, and H. Distl, "Real-time controlled tuned mass dampers for Wolgograd Bridge", Beton-Und Stahlbetonbau, vol. 108, pp. 362-372, 2013.

[59] C. Seiler, O. Fisher, and P. Huber, "Semi-active MR dampers in TMD's for vibration control of footbridges - part 2: numerical analysis and practical realization", in Proceedings of the International Conference on the Design and Dynamic Behaviour of Footbridges, Paris, France, November 20-22, 2002.

[60] M. Setareh, et al., "Semiactive tuned mass damper for floor vibration control", Journal of Structural Engineering, vol. 133, issue 2, pp. 242-250, 2007.

[61] S. Nagarajaiah, "Adaptive passive, semiactive, smart tuned mass dampers: identification and control using empirical mode decomposition, Hilbert transform, and short-term Fourier transform", Structural Control and Health Monitoring, vol. 16, issue 7-8, pp. 800-841, 2009.

[62] B. Spencer, and S. Nagarajaiah, "State of the art of structural control", Journal of Structural Engineering, vol. 129, issue 7, pp. 845-856, 2003.

[63] B T. Pinkaew, and Y. Fujino, "Effectiveness of semi-active tuned mass dampers under harmonic excitation”, Engineering Structures, vol. 23, issue 7, pp. 850-856, 2001.

[64] P. L. Walsh, and J. S. Lamancusa, "A variable stiffness vibration absorber for minimization of transient vibrations", Journal of Sound and Vibration, vol. 158, issue 2, pp. 195-211, 1992.

[65] H. Hu, and D. Jin, "A semi-active vibration control strategy based on piecewise linear vibration absorbers", Journal of Vibration Engineering, vol. 10, issue 2, pp. 125-130, 1997.

[66] X. Qian, and H. Hu, "A semi-active vibration absorber with an adjustable clearance and its realization", Journal of Vibration Engineering, vol. 14, issue 4, pp. 378-381, 2001.

[67] J. H. Koo, and M. Ahmadian, "In search of suitable control methods for semi-active tuned vibration absorbers", Journal of Vibration and Control, vol. 10, issue 2, pp. 163-174, 2004.

[68] F. Allen, and R. Karjalainen, "Using genetic algorithms to find technical trading rules", Journal of financial economics, vol. 51, pp. 245-271, 1999.

[69] M W. Y. Fowlkes, and C. M. Creveling, Engineering methods for robust product design: using Taguchi methods in technology and product development. Reading, MA: Addison-Wesley Publishing Company, 1995.

[70] C. Zang, M. I. Friswell, and J. E. Mottershead, "A review of robust optimal design and its application in dynamics", Computers and Structures, vol. 83, pp. 315-326, 2005.

[71] C. Moutinho, "Testing a simple control law to reduce broadband frequency harmonic vibrations using semi-active tuned mass dampers", Smart Materials and Structures, vol. 24, no. 5, 055007, 2015.

[72] Y. Shena, and M. Ahmadian, "Nonlinear dynamical analysis on four semi-active dynamic vibration absorbers with time delay", Shock and Vibration, vol. 20, pp. 649-663, 2013.

[73] B. Diveyev, et al., "Dynamichnyi hasnyk kolyvan" ["Dynamic Vibration Absorber"], UA Patent 114978, March 25, 2017. [in Ukrainian].

[74] B. Diveyev, et al., "Dynamichnyi hasnyk kolyvan” [“Dynamic Vibration Absorber”], UA Patent 121562, December 11, 2017. [in Ukrainian].

[75] A. Herbst, and P. Wolf, "Spray deposit distribution from agricultural boom sprayers in dynamic conditions", in Proceedings of the 25th International Conference on Noise and Vibration Engineering, Leuven, Belgium, 2000, pp. 1599-1605.

[76] D. Ooms, F. Lebeau, R. Ruter, and M. F. Destain, "Measurements of the horizontal sprayer boom movements by sensor data fusion", Computers and Electronics in Agriculture, vol. 33, issue 2, pp. 139-162, 2002.

[77] B. Diveyev, et al., "Modern methods for optimum designing of technological machines", in Proceedings of the VI Konferrencja naukowo-praktyczna "Energia w nauce i technice”, Bialostock, Poland, 2007, pp. 13-20

[78] B. Diveyev, I. Vikovych, "Application of complex methods for optimum designing mobile vehicles", in Proceedings of the XXIII Symp. Drgania w ukladach fizycznch, Poznan-Bedlewo, Poland, 2008, pp. 64-67.

[79] B. Diveyev, I. Vikovych, I. Dorosh, and I. Kernytskyy, "Different type vibration absorbers design for beam-like structures", in Proceedings of the 19th International Congress on Sound and Vibration, Vilnius, Lithuania, 2012, pp. 1499-1507.

[80] B. Diveyev, I. Vikovych, V. Martyn, and I. Dorosh, "Optimization of the impact and particle vibration absorbers", in Proceedings of the 22nd International Congress on Sound and Vibration, Florence, Italy, 2015, Code 121474. 